\title{
An autoinhibitory clamp of actin assembly constrains and directs synaptic endocytosis
}

\author{
Steven J. Del Signore ${ }^{a}$, Charlotte F. Kelleya, Emily M. Messelaara, Tania Lemos ${ }^{\text {a }}$, Michelle F. Marchan ${ }^{\text {a }}$, \\ Biljana Ermanoska ${ }^{a}$, Markus Mund ${ }^{\text {b }}$, Thomas G. Fai ${ }^{\text {c }}$, Marko Kaksonen ${ }^{\text {b }}$, Avital A Rodala ${ }^{\text {a }}$ \\ a Department of Biology, Brandeis University, 415 South St. Waltham MA USA \\ b Department of Biochemistry and NCCR Chemical Biology, University of Geneva, 30 Quai Ernest-Ansermet, 1211 Geneva, \\ Switzerland \\ ${ }^{\mathrm{c}}$ Department of Mathematics, Brandeis University, 415 South St. Waltham MA USA \\ ${ }^{1}$ Correspondence: arodal@brandeis.edu, Brandeis University 415 South St MS029 Waltham MA 02454 781-736-2459
}

\begin{abstract}
Synaptic membrane-remodeling events such as endocytosis require force-generating actin assembly. The endocytic machinery that regulates these actin and membrane dynamics localizes at high concentrations to large areas of the presynaptic membrane, but actin assembly and productive endocytosis are far more restricted in space and time. Here we describe a mechanism whereby autoinhibition clamps the presynaptic endocytic machinery to limit actin assembly to discrete functional events. We found that collective interactions between the Drosophila endocytic proteins Nwk/FCHSD2, Dap160/Intersectin, and WASp relieve Nwk autoinhibition and promote robust membrane-coupled actin assembly in vitro. Using automated particle tracking to quantify synaptic actin dynamics in vivo, we discovered that Nwk-Dap160 interactions constrain spurious assembly of WASp-dependent actin structures. These interactions also promote synaptic endocytosis, suggesting that autoinhibition both clamps and primes the synaptic endocytic machinery, thereby constraining actin assembly to drive productive membrane remodeling in response to physiological cues.
\end{abstract}

Keywords: Endocytosis, actin, synapse, WASp, Intersectin, Dap160, Nervous Wreck, FCHSD2

\section{Introduction}

At neuronal presynaptic terminals, actin assembly affects many physiological processes including synapse morphogenesis, traffic of numerous vesicular cargoes, and synaptic vesicle endocytosis, organization, and mobility (Dillon and Goda, 2005; Nelson et al., 2013; Papandréou and Leterrier, 2018). However, the molecular mechanisms that control F-actin dynamics in space and time at presynaptic membranes are largely unknown. Presynaptic terminals maintain constitutively high local concentrations of actin-associated endocytic regulatory proteins at synaptic membranes (Reshetniak et al., 2020; Wilhelm et al., 2014), yet only a small fraction of this protein pool is likely to be active at any point in time (in response to vesicle release) and space (at $<100 \mathrm{~nm}$ diameter endocytic sites), suggesting that the endocytic machinery is held in an inactive state at synaptic membranes. However, we do not know the mechanisms that maintain this machinery in an inactive state at the membrane, or how it is activated when and where it is needed.

One plausible mechanism to restrict membrane-cytoskeleton remodeling and endocytic activity to specific locations and times may lie in autoinhibition, which is a property of multiple endocytic proteins (Gerth et al., 2017; Kim et al., 2000; Rao et al., 2010; Stanishneva-Konovalova et al., 2016). One example is the F-BAR-SH3 protein Nervous Wreck (Nwk), which regulates synaptic membrane traffic at the Drosophila neuromuscular junction (NMJ) (Coyle et al., 2004; O'Connor-Giles et al., 2008; Rodal et al., 2008, 2011; Ukken et al., 2016) and whose mammalian homolog FCHSD2 regulates endocytosis and endocytic traffic in mammalian cells (Almeida-Souza et al., 2018; Xiao and Schmid, 2020; Xiao et al., 2018). Nwk/FCHSD2 proteins couple two activities: membrane remodeling and WASp-dependent actin polymerization (Almeida-Souza et al., 2018; Rodal et al., 2008; Stanishneva-Konovalova et al., 2016). Intramolecular autoinhibitory interactions between the Nwk F-BAR and its two SH3 domains mutually inhibit both Nwk membrane binding and activation of WASp (Stanishneva-Konovalova et al., 2016). Unlike other F-BAR-SH3 proteins, which are completely released from autoinhibition upon membrane binding (Guerrier et al., 2009; Meinecke et al., 2013; Rao et al., 2010), the SH3b domain of Nwk continues to restrict SH3a-mediated WASp activation even after Nwk binds membranes (StanishnevaKonovalova et al., 2016). This suggests that autoinhibition allows NwkWASp to remain inactive even after recruitment to the membrane, thus keeping the endocytic machinery in a primed but inactive state. We hypothesized that additional binding partners of $\mathrm{Nwk}^{\mathrm{SH} 3 \mathrm{~b}}$ may be required to fully activate membrane remodeling at discrete times and locations at the synapse.

An excellent candidate for release of Nwk autoinhibition at synapses is the endocytic adapter Intersectin (Dap160 in Drosophila). Intersectin interacts with numerous endocytic proteins to regulate endocytosis in mammalian cells (Henne et al., 2010; Okamoto et al., 1999; Praefcke et al., 2004; Pucharcos et al., 2000; Schmid et al., 2006; Sengar et al., 1999; Teckchandani et al., 2012), and has been implicated in several steps of the synaptic vesicle cycle (Evergren et al., 2007; Gerth et al., 2017; Jäpel et al., 2020; Pechstein et al., 2010, 2015). Of particular note, Intersectin recruits the Nwk homolog FCHSD2 to sites of endocytosis (AlmeidaSouza et al., 2018), though it is not yet known how this affects FCHSD2 autoinhibition. In Drosophila, Dap160 interacts with WASp, Nwk, and other membrane remodeling proteins via its four SH3 domains (SH3A-D), and regulates the levels and localization of many of these proteins, including Nwk (Koh et al., 2004; Marie et al., 2004; Roos and Kelly, 1998). Further, dap160 mutant phenotypes overlap with those of Nwk and WASp mutants, including impaired synaptic vesicle cycling and synaptic overgrowth (Coyle et al., 2004; Khuong et al., 2010; Koh et al., 2004; Marie et al., 2004). Finally, Intersectin and Dap160 shift 
Del Signore et al., 1242020 - BioRxiv

localization from synaptic vesicle pools to the plasma membrane in response to synaptic activity (Evergren et al., 2007; Gerth et al., 2017; Winther et al., 2015), suggesting that Dap160 may provide the spatiotemporal link between salient physiological triggers and Nwk/WASp activation.

The high concentration and broad membrane distribution of inactive endocytic proteins (Reshetniak et al, 2020; Wilhelm et al, 2014) make it difficult to characterize the molecular dynamics of synaptic endocytosis. To overcome this barrier, we quantified discrete actin assembly events at the Drosophila NMJ as a proxy for productive endocytosis, as actin assembly is both a primary target of the endocytic apparatus under investigation, and is required for synaptic vesicle endocytosis in all forms, including at the Drosophila NMJ (Kononenko et al., 2014; Wang et al., 2010; Wu et al., 2016). This synapse is an ideal system to investigate the molecular dynamics of the endocytic machinery due to its large size, ease of genetic manipulation, and accessibility to live and super-resolution imaging. Here we combine in vitro biochemical approaches with quantitative imaging at the NMJ to define the interactions among Dap160, Nwk, and WASp that relieve autoinhibition. These interactions drive robust membrane-associated actin assembly in vitro, regulate the frequency and dynamics of synaptic actin structures in vivo, and are functionally required for normal endocytosis at the NMJ.

\section{Results}

Actin assembles in discrete dynamic patches despite broad distribution of presynaptic membrane-cytoskeleton remodeling machinery

While the importance of actin in synaptic endocytosis is clear (Kononenko et al., 2014; Wang et al., 2010; Wu et al., 2016), until now there has been no quantitative analysis of individual actin-dependent membrane-remodeling events at synapses. To better understand presynaptic F-actin dynamics and to identify sites where the cytoskeleton and membrane remodeling machinery is active, we quantified individual F-actin assembly events by spinning disk confocal microscopy of NMJs presynaptically expressing fluorescent actin probes. We performed these experiments under resting conditions, where vesicle release is spontaneous at a rate of $\sim 5-6$ vesicles $/ 10 \mu \mathrm{m}^{2} / \mathrm{min}$ (Akbergenova et al., 2018; Melom et al., 2013), presumably requiring a similar rate of compensatory endocytosis (Sabeva et al., 2017). We compared GFP::actin, a GFP-tagged moesin F-actin binding domain (GMA), and Lifeact::Ruby. The predominant structures labeled by all of these markers at the presynaptic membrane were transient patches (Movie 1, Fig 1A, Fig 1 S1A), as has been previously observed (Nunes et al., 2006; Pawson et al., 2008; Piccioli and Littleton, 2014). We then quantified individual actin patch dynamics using automated particle tracking and quantification (Berro and Pollard, 2014), which captured on the order of $30-50 \%$ of visible actin structures (see methods for more detail). Imaging at $0.25 \mathrm{~Hz}$, we found an average of $1.2 \mathrm{GMA}$ patches $/ 10 \mu \mathrm{m}^{2} / \mathrm{min}$, exhibiting a mean duration of $48.0 \mathrm{sec}+/-45.6 \mathrm{sec}$, with an average relative amplitude of $68 \%+/-32 \%\left(\left(\mathrm{I}_{\max }-\mathrm{I}_{\min }\right) / \mathrm{I}_{\text {mean }}\right)$ (Fig 1B-D). Quantification of GFP::actin and lifeact::Ruby showed very similar dynamics to GMA, suggesting that these measurements robustly reflect the underlying actin dynamics and not the specific properties of a particular probe. As we noted a strong floor effect with short-duration patches, we also performed imaging at $1 \mathrm{~Hz}$, which could not capture the entire lifetime distribution due to photobleaching but was able to identify a larger population of short duration patches (Fig 1S1B) with an average duration of $\sim 16+/-20$ seconds. Given this range of measurements at different sampling frequencies and the efficiency of our automated detection, we estimate that patch frequency is between $2.8-10.3$ events/10 $\mu \mathrm{m}^{2} / \mathrm{min}$ (see Methods for calculations), on par with the expected frequency of endocytic events, and with a similar albeit broader distribution of durations compared to yeast (15 seconds; Berro and Pollard, 2014) and mammalian cells ( 40 seconds; Taylor et al., 2011).

We next examined the molecular determinants of synaptic actin patch assembly. Patches strongly co-labeled with Arp3::GFP (Manders' coefficient of 0.81 (Lifeact:Arp3), (Fig 1E-F)), suggesting they are predominantly composed of branched F-actin, similar to sites of endocytosis in other cell types (Akamatsu et al., 2020; Collins et al., 2011). To test whether synaptic actin patches require Arp $2 / 3$ activation, we analyzed patch dynamics in larvae lacking the Arp $2 / 3$ activator WASp. We compared a genomic mutant (Fig 1G-I), likely hypomorphic due to maternal contribution (Ben-Yaacov et al., 2001)) to presynaptic depletion in neurons expressing WASp RNAi (Fig 1 S1C-E). Using both approaches allows us to distinguish neuron-autonomous from nonautonomous effects of WASP, which is present both pre- and postsynaptically (Coyle et al., 2004). Both genomic and RNAi manipulations significantly reduced the number of actin patches, while genomic mutants also skewed the distribution of patch durations towards both shorter and longer events (Fig 1I). These differences could reflect variable loss of function between the RNAi and mutant, or identify separable presynaptic autonomous (patch frequency), vs nonautonomous (patch duration) effects of WASp. Overall, these data clearly indicate that WASp is autonomously required in neurons to initiate assembly of presynaptic actin patches, similar to its involvement in endocytosis in yeast, mammalian non-neuronal cells, and in the NMJ (Hussain et al., 2001; Kessels and Qualmann, 2004; Khuong et al., 2010; Madania et al., 1999).

We next examined the synaptic distribution of two likely WASp regulators, Nwk and Dap160. By conventional and super-resolution microscopy of neurons in diverse organisms, these and other presynaptic membrane remodeling proteins localize to a broad membrane domain surrounding active zones, termed the periactive zone (PAZ) (Coyle et al., 2004; Denker et al., 2011; Gerth et al., 2017; Koh et al., 2004; Marie et al., 2004; Sone et al., 2000). Consistent with these prior descriptions, we observed by structured illumination microscopy (SIM) that the PAZ proteins Nwk and Dap160 localize to a membrane-proximal mesh that surrounds active zones, which were labeled with Bruchpilot (BRP, Fig 2A). We observed similar results by live imaging of an endogenously tagged Nwk protein by SIM, which revealed the vast majority of protein to be in close proximity to the plasma membrane (Fig 2B). We then compared the localization of PAZ proteins to F-actin patches at the NMJ. As expected, actin patches were much sparser than the endocytic machinery, and GMA-labeled patches only partially overlapped with each of presynaptic WASp, Nwk, and Dap160 (Fig 2C-F); Manders' coefficients of $0.45,0.59,0.53$, respectively). These data confirm that, in sharp contrast to the actin regulatory machinery, which localizes broadly across the PAZ, actin assembly itself is much sparser both spatially and temporally at the NMJ. This raises the question of how PAZ machinery might itself be locally regulated to promote the formation of productive synaptic actin assemblies. 
bioRxiv preprint doi: https://doi.org/10.1101/2020.03.06.981076; this version posted December 5, 2020. The copyright holder for this preprint (which was not certified by peer review) is the author/funder, who has granted bioRxiv a license to display the preprint in perpetuity. It is made available under aCC-BY-NC-ND 4.0 International license.

Del Signore et al., 1242020 - BioRxiv

A

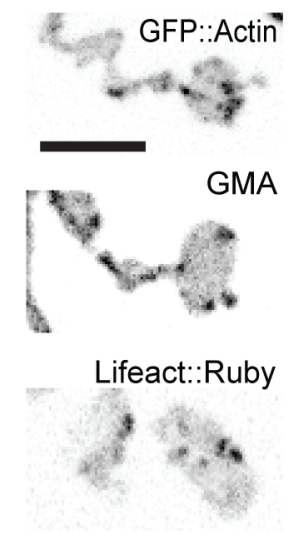

E

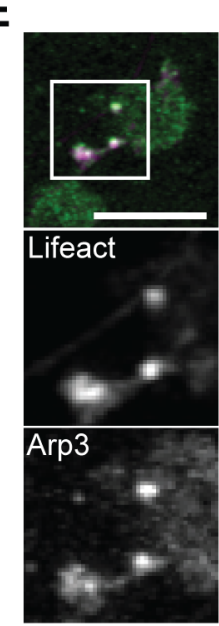

$\mathbf{F}$

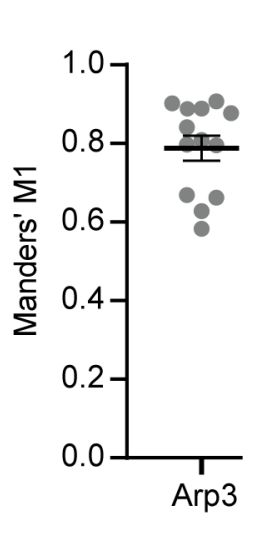

C

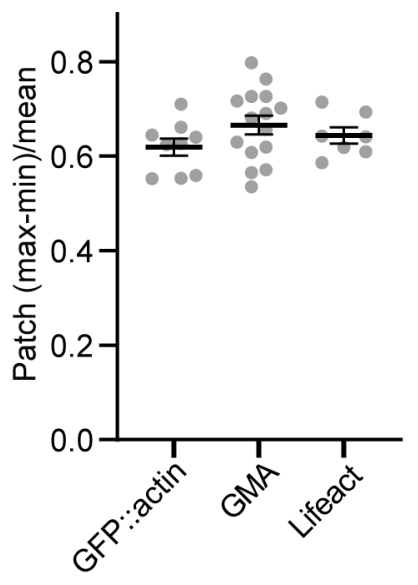

G

$\mathrm{H}$
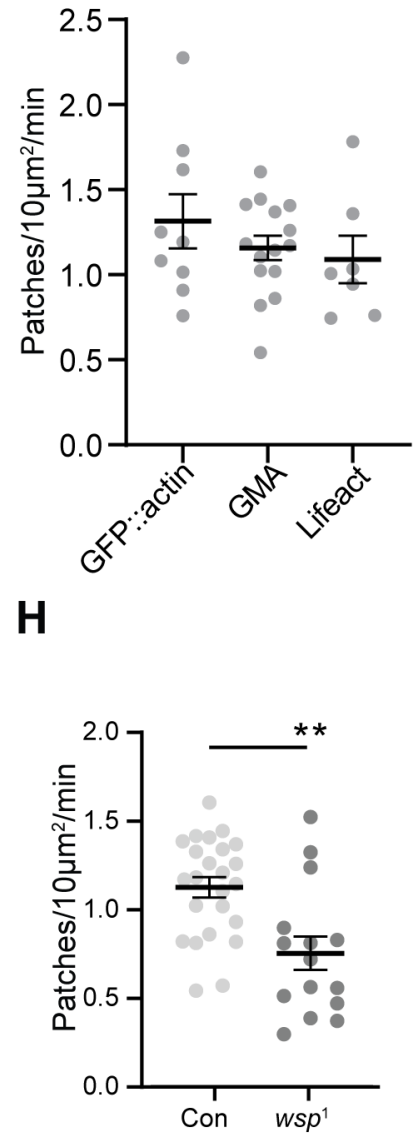

D

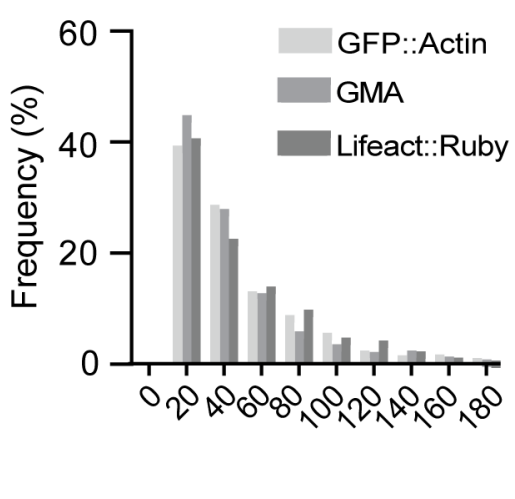

I

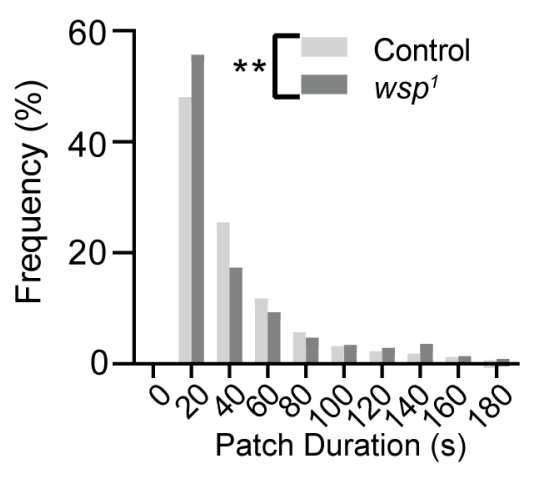

Lifeact GFP::Arp3

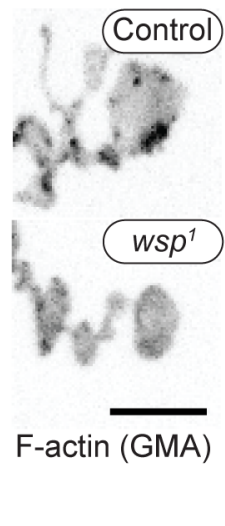

Figure 1

Figure 1. Dynamics of synaptic actin structures are consistent with endocytic function. (A) Representative MaxIPs of single spinning disk confocal microscopy time points, showing C155-Gal4-driven actin probes: GFP::actin, GMA, and Lifeact::Ruby. (B-D) Automatic detection and analysis of movies acquired at $.25 \mathrm{~Hz}$ of $\mathrm{F}$-actin patch intensity amplitude (B), frequency (C), and duration distribution (D) show similar dynamics for different reporters. (E-F) MaxIPs (Airyscan microscopy) of a single frame of muscle 6/7 NMJ expressing Lifeact::ruby (magenta) and Arp3::GFP (green). Actin patches colocalize extensively with Arp3::GFP. (F) Quantification of colocalization by Manders' coefficients. Graph shows mean +/- s.e.m.; n represents NMJs. (G-I) Patch assembly requires the Arp2/3 activator WASp. GMA patch dynamics in control and WASp mutant animals imaged at $.25 \mathrm{~Hz}$. (G) MaxIPs of single spinning disk confocal microscopy time points, showing pan-neuronally expressed GMA localization in control and wsp ${ }^{1}$ mutant muscle 6/7 NMJs. (H) Quantification of patch frequency. Graph shows mean +/- s.e.m.; n represents NMJs. (I) Quantification of patch duration distribution. Bins are 20 sec; $X$ axis values represent bin centers. $n$ represents patches. Scale bars in A, E, G, are $5 \mu \mathrm{m}$. Associated with Fig. 1 S1 and Movie 1. 
bioRxiv preprint doi: https://doi.org/10.1101/2020.03.06.981076; this version posted December 5, 2020. The copyright holder for this preprint (which was not certified by peer review) is the author/funder, who has granted bioRxiv a license to display the preprint in perpetuity. It is made available under aCC-BY-NC-ND 4.0 International license.

Del Signore et al., 1242020 - BioRxiv

A

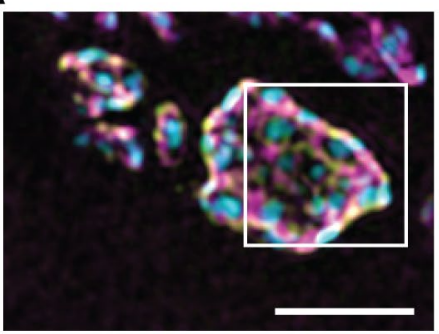

Nwk Dap160 Active Zones (BRP)

C

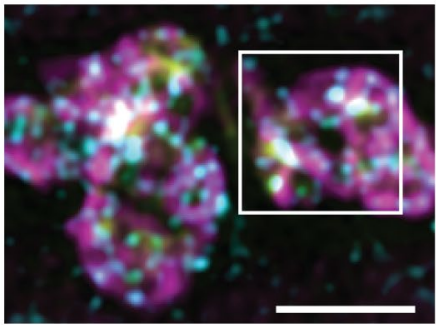

Nwk F-actin (GMA) WASp::myc

E

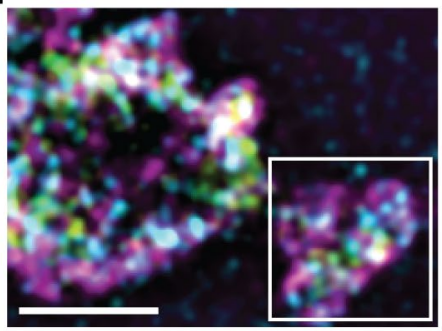

Dap160 F-actin (GMA) WASp::myc
B
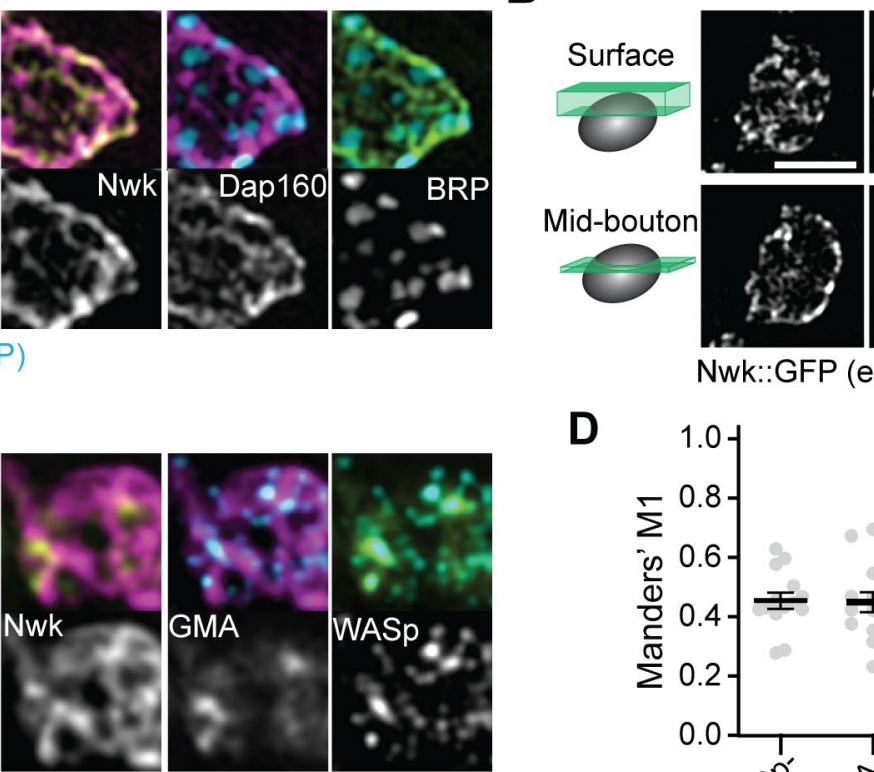

Figure 2
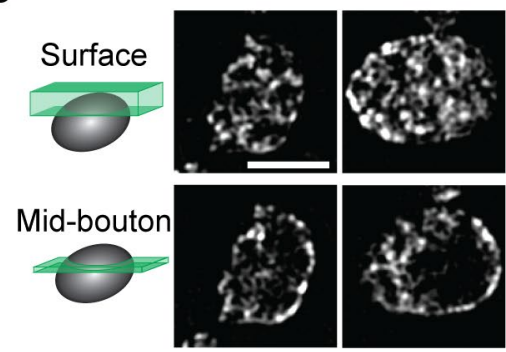

Nwk::GFP (endogenous)

D

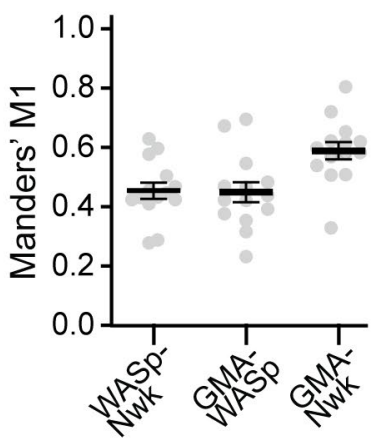

F

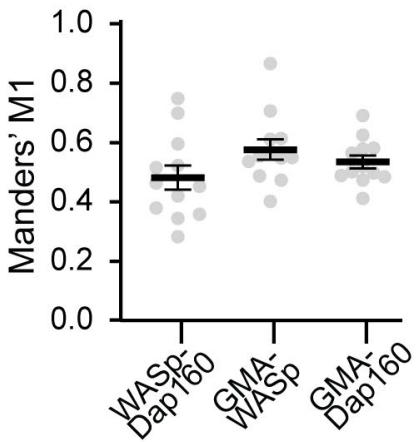

Figure 2. Periactive zone proteins accumulate broadly across the NMJ. (A-B) The periactive zone (PAZ) proteins Nwk (magenta) and Dap160 (green) accumulate in a micron-scale mesh adjacent to active zones (AZ) (Bruchpilot, blue). Image shows maximum intensity projection (MaxIP) of a structured illumination microscopy (SIM) Z-stack. (B) Surface projection (top) and medial optical section (bottom) SIM images of live-imaged endogenous Nwk::GFP showing abundant and specific membrane recruitment, similar to fixed imaging. (C-F) PAZ proteins partially colocalize with actin patches. Optical slices of SIM micrographs showing F-actin (labeled with GMA) localization with presynaptically expressed WASp::Myc and Nwk (C) or Dap160 (E). (D,F) Quantification of colocalization between GMA and WASp::Myc, and Nwk (D), or Dap160 (F). (D,F) Graphs show mean +/- s.e.m.; n represents NMJs. Associated with Fig $1 \mathrm{S1.}$ 
bioRxiv preprint doi: https://doi.org/10.1101/2020.03.06.981076; this version posted December 5, 2020. The copyright holder for this preprint (which was not certified by peer review) is the author/funder, who has granted bioRxiv a license to display the preprint in perpetuity. It is made available under aCC-BY-NC-ND 4.0 International license.

Del Signore et al., 1242020 - BioRxiv

A

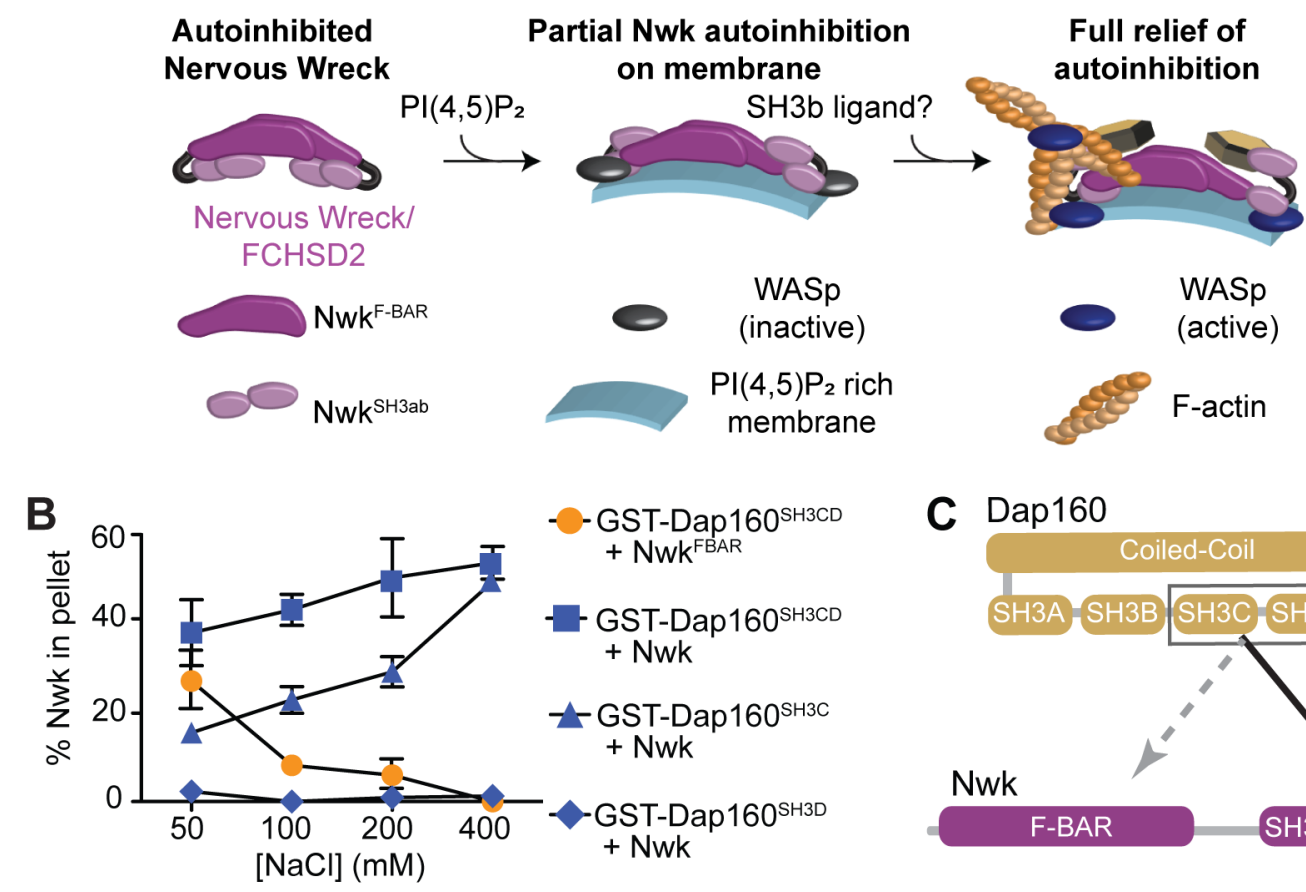

Figure 3
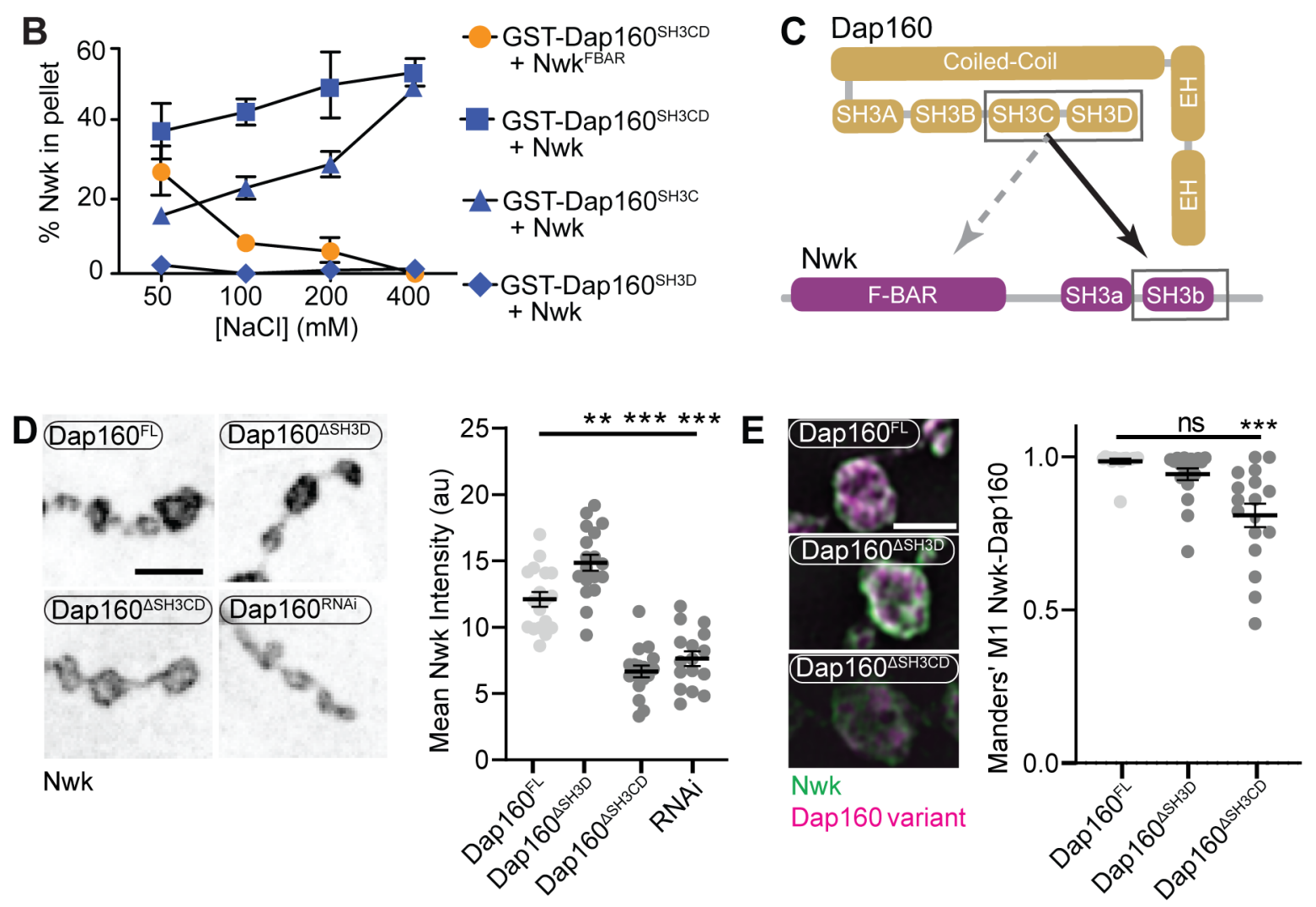

Figure 3. Distinct SH3-SH3 and SH3-BAR domain interactions drive Dap160-Nwk association in vitro and at synapses. (A) Model for autoinhibition of Nwk membrane binding and WASp activation. Neither membrane-bound nor membrane-free Nwk efficiently activate WASp-mediated actin polymerization, due to persistent SH3b-mediated autoinhibitory interactions, suggesting that an SH3b domain ligand is required for activation. (B) Dap $160^{\mathrm{SH} 3 \mathrm{CD}}$ exhibits electrostatic and hydrophobic interactions with the Nwk F-BAR and SH3 domains, respectively. GST fusion proteins were immobilized on glutathione agarose and incubated with the indicated purified proteins. Pellets and supernatants were fractionated by SDS-PAGE, Coomassie stained, and quantified by densitometry. Graphs show the average +/- s.e.m. of three independent reactions. [Nwk $\left.{ }^{\mathrm{F}-\mathrm{BAR}}\right]=1.5 \mu \mathrm{M}$, [Nwk]=.8 $\mu \mathrm{M}$, [GSTDap $\left.160^{\mathrm{SH} 3 \mathrm{CD}}\right]=1.6 \mu \mathrm{M}$, [GST-Dap $\left.160^{\mathrm{SH} / \mathrm{C} / \mathrm{D}}\right]=1.2 \mu \mathrm{M}$. (C) Summary of Dap160 ${ }^{\mathrm{SH} 3 \mathrm{CD}}-\mathrm{Nwk}^{\mathrm{SH} 3 a b}$ interactions. Gray and black arrows indicate electrostatic and hydrophobic interactions, respectively (D) MaxIP spinning disc confocal or (E) MaxIP SIM micrographs of muscle 4 NMJs expressing C155-GAL4-driven UAS-Dap160 rescue transgene variants in a dap160 null background (dap160 $1 / 1 \mathrm{Df})$. Loss of the Dap160 ${ }^{\mathrm{SH} 3 \mathrm{CD}}$ domains (Dap160 ${ }^{\Delta \mathrm{SH} 3 \mathrm{CD}}$ ), but not the SH3D domain alone $\left(\right.$ Dap $\left.160^{\Delta \mathrm{SH} 3 \mathrm{D}}\right)$, disrupts normal Nwk accumulation (D, right) and Dap160-Nwk colocalization (E, right) at synapses. Graphs show mean +/s.e.m.; n represents NMJs. Associated with Fig S3S1-2. 
bioRxiv preprint doi: https://doi.org/10.1101/2020.03.06.981076; this version posted December 5, 2020. The copyright holder for this preprint (which was not certified by peer review) is the author/funder, who has granted bioRxiv a license to display the preprint in perpetuity. It is made available under aCC-BY-NC-ND 4.0 International license.

Del Signore et al., 1242020 - BioRxiv

\section{Multiple interaction interfaces between Dap160 and Nwk regulate Nwk autoinhibition}

The hypothesis that PAZ protein-mediated actin assembly might be locally activated is particularly interesting given that we and others have previously shown that autoinhibition of both Nwk and its mammalian homolog FCHSD2 suppresses both WASp activation and membrane binding (See Fig 3A for summary model; Almeida-Souza et al., 2018; Rodal et al., 2008; Stanishneva-Konovalova et al., 2016). These results suggest that transient or localized relief of autoinhibition could explain how the PAZ controls actin assembly. To determine if and how the candidate activator Dap160 might relieve Nwk autoinhibition, we first mapped their specific interaction domains using GST pulldown assays,
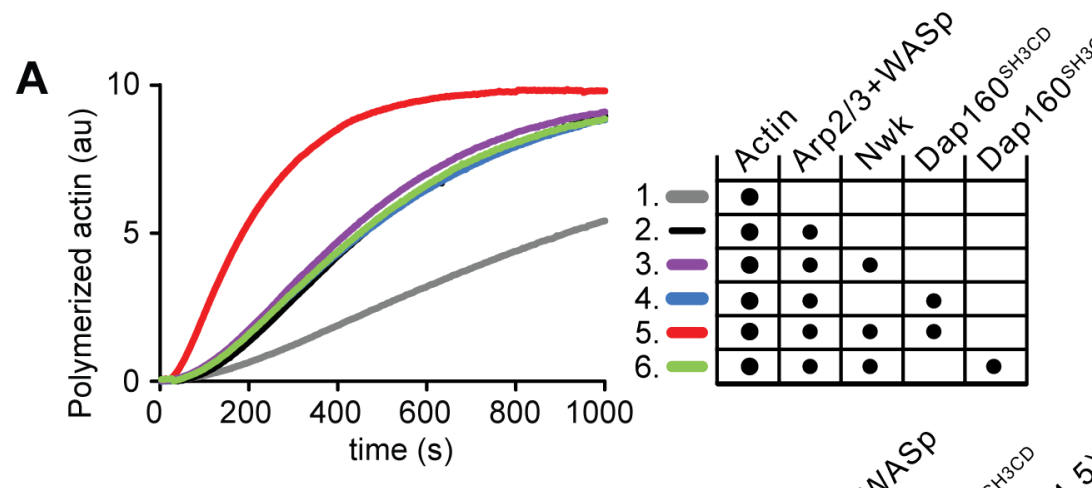

B

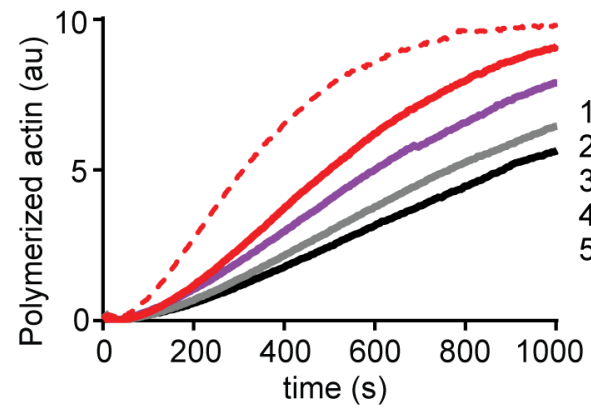

C

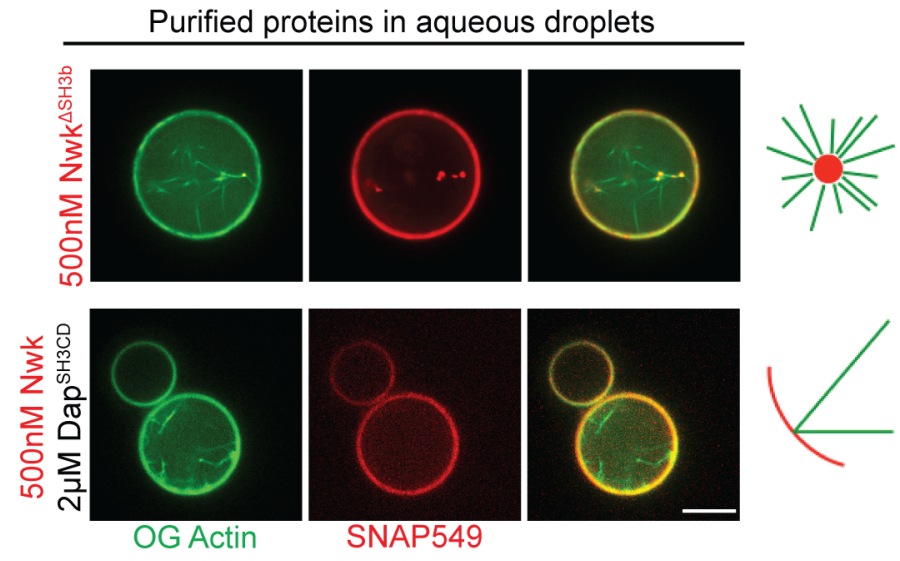

Figure 4
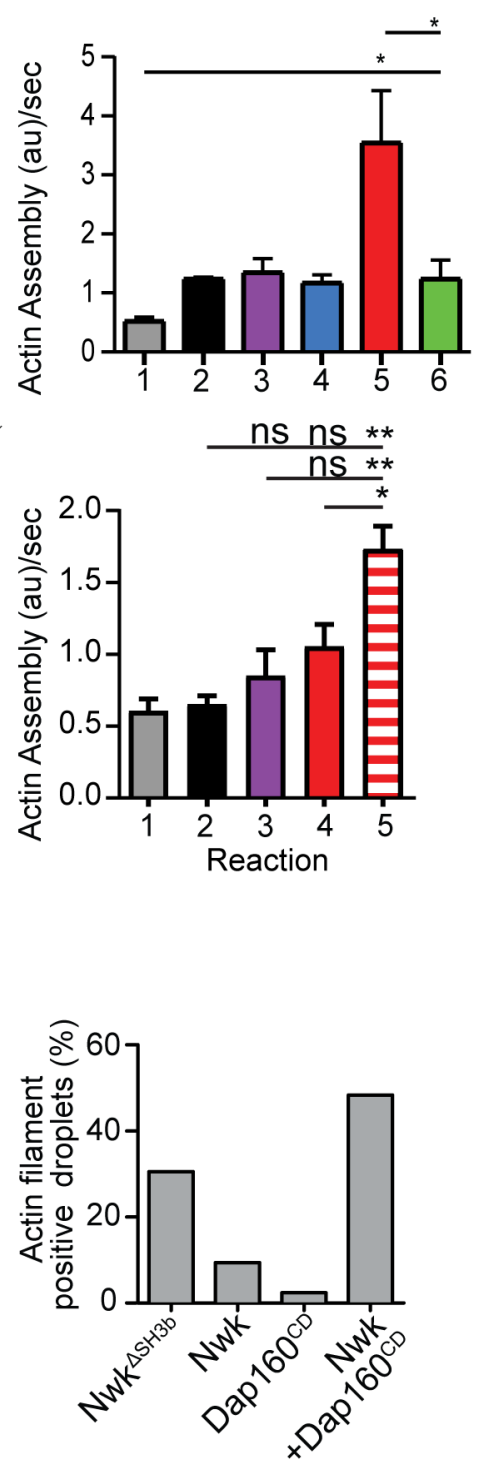

Figure 4. Nwk, Dap160, and PI(4,5) $P_{2}$ potentiate WASp-mediated actin assembly at membranes. (A-B) Pyrene actin assembly assay $(2.5 \mu \mathrm{M}$ actin, $5 \%$ pyrene labeled). Curves are representative single experiments demonstrating actin assembly kinetics; graphs represent rates calculated from the linear range of assembly from at least two independent experiments. (A) The combination (red trace) of Nwk and Dap $160^{\mathrm{SH} 3 \mathrm{CD}}$ together enhance WASp-Arp2/3 mediated actin assembly. Either alone (magenta and blue traces) has no effect on WASp activity. [Nwk] $=500 \mathrm{nM},[\mathrm{Dap} 160]=2 \mu \mathrm{M}$, $[\mathrm{WASp}]=50 \mathrm{nM},[\mathrm{Arp} 2 / 3]=50 \mathrm{nM}$. (B) PI(4,5) $\mathrm{P}_{2}$ enhances Nwk-Dap160 activation of WASp-mediated actin assembly. Nwk alone or in combination with $10 \% \mathrm{PI}(4,5) \mathrm{P}_{2}$ liposomes fails to activate WASp, while the addition of Dap $160^{\mathrm{SH} 3 \mathrm{CD}}$ and $\mathrm{PI}(4,5) \mathrm{P}_{2}$ synergistically enhance WASp-mediated actin assembly. [Nwk] $=100 \mathrm{nM}$, [Dap160] $=500 \mathrm{nM}$, [WASp] $=50 \mathrm{nM}$, [Arp2/3] $=50 \mathrm{nM}$. (C) Single slices from spinning disc confocal micrographs of water-droplet actin assembly assay: SNAP labeled Nwk constructs (red) and Oregon Green actin (green) were mixed with the indicated proteins in aqueous solution and emulsified in $97.5 \%$ DPHPC, $2.5 \% \mathrm{PI}(4,5) \mathrm{P}_{2}$ in decane. Both deregulated Nwk ${ }^{\Delta \mathrm{SH} 3 \mathrm{~b}}$ and $\mathrm{Nwk}+\mathrm{Dap} 160^{\mathrm{SH} 3 \mathrm{CD}}$ promote F-actin assembly in droplets. However, while Nwk- Dap $160^{\mathrm{SH} 3 \mathrm{CD}}$ derived F-actin associates with the lipid interface, de-regulated Nwk ${ }^{\Delta \mathrm{SH} 3 \mathrm{~b}}$ promotes actin assembly from asters that do not associate with membrane. $\left[\mathrm{Nwk}^{1-\mathrm{xxx}}\right]=500 \mathrm{nM}$, [Dap160] $=2 \mu \mathrm{M},[\mathrm{WASp}]=50 \mathrm{nM}$, [Arp2/3] $=50 \mathrm{nM}$. Graph indicates percentage of droplets with observable actin filament assembly. Scale bar in $\mathrm{C}$ is $10 \mu \mathrm{m}$. 
bioRxiv preprint doi: https://doi.org/10.1101/2020.03.06.981076; this version posted December 5, 2020. The copyright holder for this preprint (which was not certified by peer review) is the author/funder, who has granted bioRxiv a license to display the preprint in perpetuity. It is made available under aCC-BY-NC-ND 4.0 International license.

Del Signore et al., 1242020 - BioRxiv

and found that purified Dap160 SH3C-containing protein fragments (SH3C, SH3CD, or SH3ABCD) directly interact with $\mathrm{Nwk}^{\mathrm{SH} 3 \mathrm{~b}}$, while SH3D alone does not (Fig 3B, Fig 3S1A-C, see Fig 3 S2A for details of constructs used). Unexpectedly, Dap160 SH3C, SH3D, and SH3CD domain fragments also each interact with the isolated Nwk F-BAR domain (Fig 3S1B). We next determined how Dap160 interactions with $\mathrm{Nwk}^{\mathrm{F}-\mathrm{BAR}}$ compared to a Nwk fragment containing the F-BAR and both SH3 domains. Dap160-Nwk ${ }^{\mathrm{F}-\mathrm{BAR}}$ interactions were progressively eliminated by increasing salt, suggesting they are mediated by electrostatic interactions. By contrast, Dap $160^{\mathrm{SH} 3 \mathrm{CD}}-\mathrm{Nwk}$ interactions were maintained (Fig 3B, Fig 3S1C), suggesting that the SH3-SH3 interaction is mediated primarily by hydrophobic interactions, consistent with their mammalian homologs (Almeida-Souza et al., 2018) (see summary of interactions, Fig 3C). Finally, we found that truncation of Dap $160^{\mathrm{SH} 3 \mathrm{CD}}$ significantly decreased the levels of Nwk in synaptic boutons (Fig 3D, Fig 3S2) as well as colocalization between Nwk and Dap160 (Fig 3E), supporting an in vivo requirement for this interaction.

\section{Dap160 ${ }^{\text {SH3CD }}$ and membranes relieve inhibition of Nwk-WASp- Arp2/3 actin assembly in vitro}

We previously showed that Nwk only weakly activates WASp-dependent actin assembly in vitro, due to Nwk autoinhibition (StanishnevaKonovalova et al., 2016). To test whether Dap $160^{\text {SH3CD }}$ might relieve Nwk autoinhibition, we performed pyrene-actin assembly assays (Fig 4). At moderate Nwk-Dap160 concentrations $(500 \mathrm{nM}$ and $2 \mathrm{um}$, respectively), Nwk and Dap $160^{\mathrm{SH} 3 \mathrm{CD}}$ significantly enhanced the rate of

\section{Figure 5}

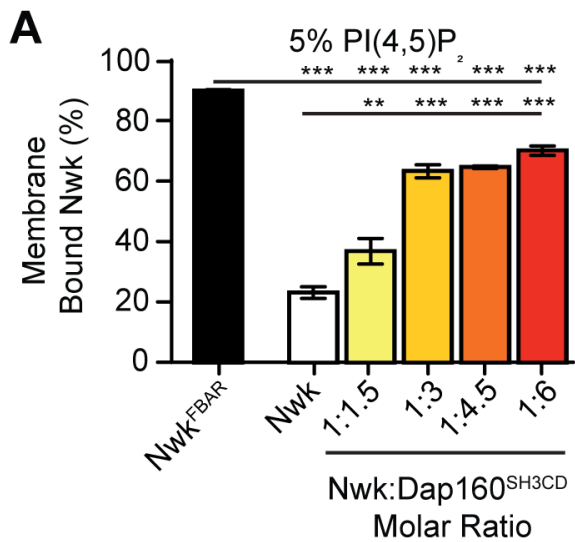

A

C

E

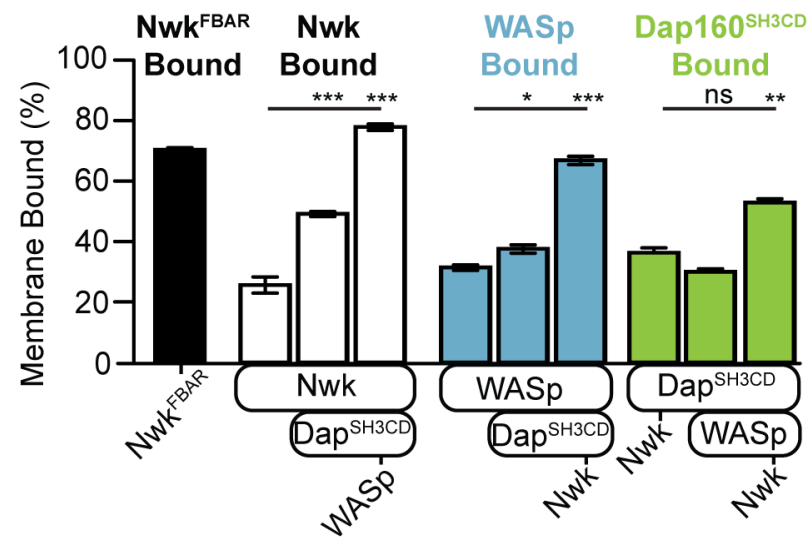

B

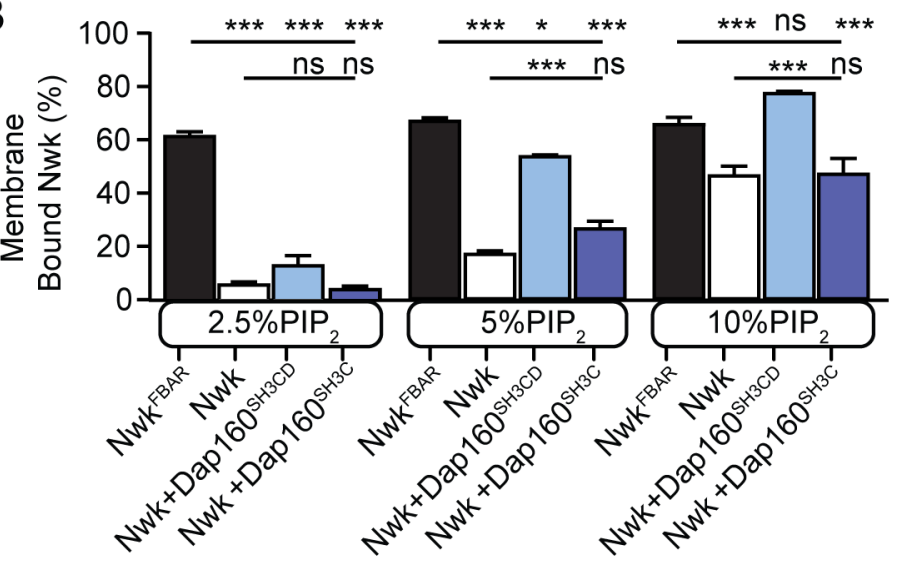

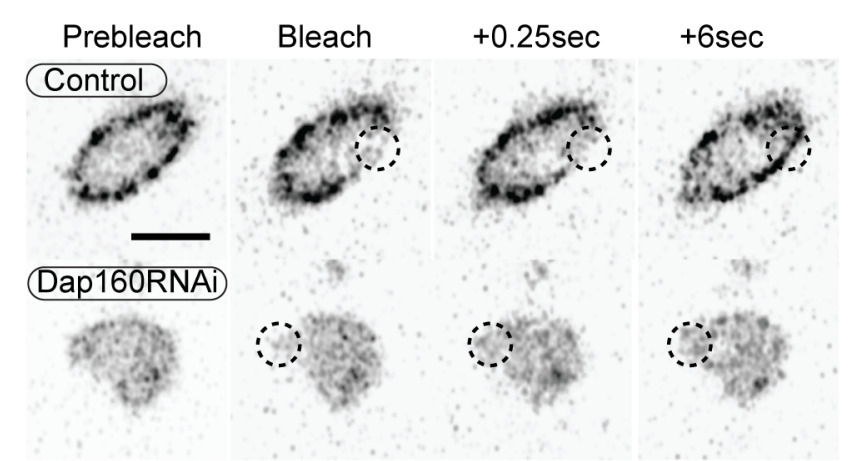

Nwk::GFP
D

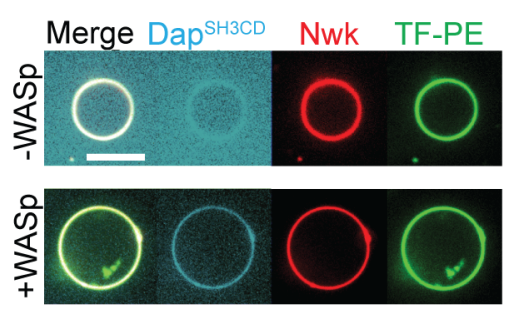

F

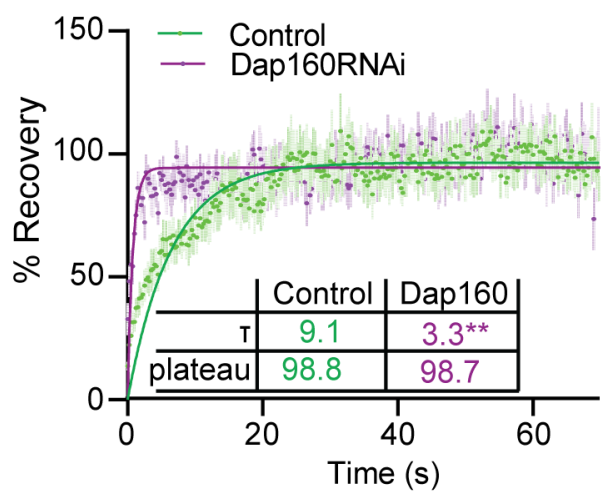


Del Signore et al., 1242020 - BioRxiv

Figure 5. Dap160 ${ }^{\mathrm{SH} 3 \mathrm{CD}}$ and WASp promote Nwk membrane association. (A-C) Liposome co-sedimentation assays between the indicated purified proteins and liposomes composed of $\left[\mathrm{mol} \%=\mathrm{DOPC} / \mathrm{DOPE} / \mathrm{DOPS} / \mathrm{PI}(4,5) \mathrm{P}_{2}=80-\mathrm{x} / 15 / 5 / \mathrm{x}\right]$, with $\mathrm{x}$ representing $\mathrm{PI}(4,5) \mathrm{P}_{2}$ concentration as noted. Quantification from Coomassie-stained gels represents the mean fraction of total protein that cosedimented with the liposome pellet, \pm SEM. (A) 1:3 Nwk:Dap $160^{\mathrm{SH} 3 \mathrm{CD}}$ saturates enhancement of Nwk membrane association at 5\% PI $(4,5) \mathrm{P}_{2}$, but not to the level of the isolated Nwk F-BAR alone $\left(\mathrm{Nwk}{ }^{\mathrm{F}-}\right.$ BAR, black bar). [Nwk $\left.{ }^{1-\mathrm{xxx}}\right]=2 \mu \mathrm{M}$, [Dap160] $=6 \mu \mathrm{M}$. (B) Dap160 ${ }^{\mathrm{SH} 3 \mathrm{CD}}$ (but not Dap160 ${ }^{\mathrm{SH} 3 \mathrm{C}}$ ) enhances Nwk association with membranes at a range of $\mathrm{PI}(4,5) \mathrm{P}_{2}$ concentrations. Maximum binding (comparable to Nwk ${ }^{\mathrm{F}-\mathrm{BAR}}$ occurs only at $5-10 \% \mathrm{PI}(4,5) \mathrm{P}_{2}$ concentrations. $\left[\mathrm{Nwk}{ }^{\mathrm{F}-\mathrm{BAR}}\right]=3 \mu \mathrm{M}$, $[\mathrm{Nwk}]=$ $1.125 \mu \mathrm{M},\left[\mathrm{Dap} 160^{\mathrm{SH} 3 \mathrm{CD}}\right]=1.7-6.8 \mu \mathrm{M}$. (C) Nwk, WASp, and Dap160 ${ }^{\mathrm{SH} 3 \mathrm{CD}}$ mutually enhance membrane recruitment. Addition of Dap160 $0^{\mathrm{SH} 3 \mathrm{CD}}$ and WASp additively enhance Nwk membrane association, while Dap $160^{\mathrm{SH} 3 \mathrm{CD}}$ and WASp show maximum recruitment to $10 \% \mathrm{PI}(4,5) \mathrm{P}_{2}$ liposomes in the presence of both other proteins. $[\mathrm{Nwk}]=1 \mu \mathrm{M}$, [WASp] $=1 \mu \mathrm{M}$, [Dap $\left.160^{\mathrm{SH} 3 \mathrm{CD}}\right]=3 \mu \mathrm{M}$. (D) GUV decoration assay, with $10 \% \mathrm{PI}(4,5) \mathrm{P}_{2} \mathrm{GUVs}$ labeled with $<1 \%$ TopFluor-PE. The addition of WASp to Nwk (red) and Dap160 $0^{\mathrm{SH} 3 \mathrm{CD}}$ (blue) enhances the recruitment of Dap160 $\mathrm{SH} 3 \mathrm{CD}$ to the membrane (green, note diffuse blue signal in (-) WASp condition). [Nwk] $=250 \mathrm{nM}$, [WASp] $=250 \mathrm{nM}$, $\left[\mathrm{Dap} 160^{\mathrm{SH} 3 \mathrm{CD}}\right]=1 \mu \mathrm{M} \mathrm{Scale}$ bar is $10 \mu \mathrm{m}$ (E-F) FRAP assay of endogenously labeled Nwk in control and C155-GAL4/UAS-Dicer driven Dap160 RNAi NMJs. Images show individual medial optical sections of Airyscan confocal images at the indicated time point. Control Nwk signal shows strong membrane association (see strong peripheral signal) and slower recovery kinetics, while loss of Dap160 eliminates the strong peripheral accumulation of Nwk::GFP and increases the recovery kinetics of Nwk::GFP in the bleached region (dashed circles). Graph shows mean +/- s.e.m. ; n represents NMJs. Scale bar is $5 \mu$ m.

WASp-Arp2/3-mediated actin assembly compared to Nwk plus WASp alone (Fig 4A). This effect is through Nwk, as Dap $160^{\mathrm{SH} 3 \mathrm{CD}}$ had no effect on WASp-Arp2/3 in the absence of Nwk. Further, Dap160 enhancement of Nwk-WASp actin assembly required the Dap $160^{\text {SH3D }}$ domain, further showing that the specific Dap160 $0^{\text {SH3D }}-N_{w k}{ }^{\mathrm{F}-\mathrm{BAR}}$ interaction relieves functional Nwk autoinhibition in vitro. Thus, multiple Nwk-Dap160 interactions work together to relieve autoinhibition of Nwk.

To generate salient physiological force, actin assembly must be coupled to membranes, and negatively charged lipids are an important ligand for both Nwk and WASp. Thus, we next tested whether addition of $\mathrm{PI}(4,5) \mathrm{P}_{2}$-rich liposomes modified actin assembly by Nwk, Dap160, and WASp (Fig 4B). Indeed, PI(4,5) $\mathrm{P}_{2}$ containing liposomes synergistically activated WASp-mediated actin assembly in concert with Dap160 and Nwk. By contrast, neither Nwk, PI(4,5) $\mathrm{P}_{2}$, or $\mathrm{Nwk}+\mathrm{PI}(4,5) \mathrm{P}_{2}$ on their own were sufficient to activate WASp above baseline (Fig 4B). Since $\mathrm{PI}(4,5) \mathrm{P}_{2}$ is also insufficient to robustly activate either WASp or Nwk under these conditions (Stanishneva-Konovalova et al., 2016), our data suggest that WASp activation reflects coordinated relief of Nwk autoinhibition by both Dap160 and membranes. To further explore the coupling between lipid association and actin assembly, we conducted Factin assembly assays in a droplet assay, in which protein-containing aqueous droplets are surrounded by a lipid interface, with lipid head groups directly contacting the aqueous phase (Fig $\mathbf{4 C}$ ). In this assay, we found that coordinated interactions among Nwk, Dap160, and WASp directed actin assembly to the lipid interface. By contrast, substitution of Nwk lacking its autoinhibitory and Dap160-interacting SH3b domain $\left(\mathrm{Nwk}^{\Delta \mathrm{SH} 3 \mathrm{~b}}\right.$ ) caused actin to assemble as free-floating asters (Fig 4C). We previously found that expression of a similarly deregulated fragment $\left(\mathrm{Nwk}^{1-631}\right)$ at the NMJ led to diffuse actin filament assembly throughout the synapse (Stanishneva-Konovalova et al., 2016). Together these data suggest that $\mathrm{Nwk}^{\mathrm{SH} 3 \mathrm{~b}}$ has a dual role of maintaining autoinhibition via Nwk-F-BAR interactions and permitting actin assembly at specific synaptic locations via Dap160-mediated activation.

\section{Dap160 and WASp relieve Nwk autoinhibition and promotes its membrane association}

Our actin assembly data suggest that membrane recruitment is a critical regulator of the Nwk-Dap160-WASp complex (Fig 4B-C). To test whether Nwk-Dap160 interactions directly regulate membrane recruitment, we performed liposome co-sedimentation assays. We found that Dap $160^{\mathrm{SH} 3 \mathrm{CD}}$ enhanced Nwk membrane binding in a dose-dependent fashion (Fig 5A). This effect depended on membrane charge, as Dap $160^{\mathrm{SH} 3 \mathrm{CD}}$ significantly enhanced Nwk membrane binding at both $5 \%$ and $10 \%$, but not at $2.5 \% \mathrm{PI}(4,5) \mathrm{P}_{2}$ (Fig 5B). Only at $10 \% \mathrm{PI}(4,5) \mathrm{P}_{2}$ did Dap $160^{\mathrm{SH} 3 \mathrm{CD}}$ promote Nwk membrane binding to the same extent as the completely uninhibited $\mathrm{Nwk}^{\mathrm{FBAR}}$ domain alone, suggesting that membrane charge and intermolecular interactions with Dap160 together tune Nwk membrane recruitment. Indeed, this effect required the full Dap $160^{\mathrm{SH} 3 \mathrm{CD}}-\mathrm{Nwk}^{\mathrm{SH} 3 \mathrm{~b}}$ interaction: Dap160 ${ }^{\mathrm{SH} 3 \mathrm{C}}$ alone was unable to promote membrane binding by Nwk, and Dap $160^{\mathrm{SH} 3 \mathrm{CD}}$ did not enhance membrane binding of Nwk lacking its Dap160-interacting SH3b domain (Fig 5S1A). These data further support the hypothesis that Dap $160^{\mathrm{SH} 3 \mathrm{CD}}$ relieves $\mathrm{Nwk}^{\mathrm{SH} 3 \mathrm{~b}}$ mediated autoinhibition.

As we found that Dap $160^{\mathrm{SH} 3 \mathrm{CD}}$ is insufficient to fully activate membrane binding by Nwk at intermediate phosphoinositide concentrations (Fig 5A), we asked whether WASp could further enhance Nwk membrane recruitment. Indeed, the addition of Dap $160^{\mathrm{SH} 3 \mathrm{CD}}$ and WASp together enhanced Nwk membrane association to the level of the isolated F-BAR domain (Fig 5C). Moreover, coordinated binding of all three components resulted in significantly enriched membrane association of both WASp and Dap160 (Fig 5C). We directly observed the coordinated recruitment of Nwk and Dap160 in the presence of WASp using fluorescently labeled proteins on GUVs (Fig 5D). Consistent with the direct Dap160-Nwk ${ }^{\mathrm{SH} 3 \mathrm{~b}}$ interaction, we found that deletion of the $\mathrm{Nwk}^{\mathrm{SH} 3 \mathrm{~b}}$ domain abolished both the Dap $160^{\mathrm{SH} 3 \mathrm{CD}}$-dependent increase and the coordinated recruitment of WASp and Dap160 (Fig 5S1A). Notably, addition of Dap160 and WASp did not change the nature of membrane deformations generated by Nwk (scalloped and pinched membranes (Becalska et al., 2013)), suggesting that Dap160 and WASp together potentiate rather than alter the inherent activity of Nwk (Fig 5S1D). These data indicate that Dap160-Nwk SH3mediated interactions potentiate Nwk association with membranes in vitro.

Finally, to test whether Dap160 promotes Nwk membrane association in vivo, we examined the dynamics of Nwk at the synapse in the presence and absence of Dap160. Knockdown of Dap160 by RNAi (Fig 5E) led to a striking loss of endogenously tagged Nwk::GFP from synaptic membranes (note strong peripheral labeling in control bouton crosssections, Fig 5E). Further, Dap160 knockdown significantly increased the rate of recovery of Nwk::GFP, consistent with a shift in localization from membrane-bound to cytosolic (Fig 5F). These data suggest that the Dap $160^{\mathrm{SH} 3 \mathrm{CD}}-\mathrm{Nwk}$ interaction promotes Nwk membrane association in vivo.

Taken together, our data indicate that multiple coordinated interactions between Nwk, WASp, Dap $160^{\mathrm{SH} 3 \mathrm{CD}}$, and membranes are required to relieve Nwk autoinhibition, allowing for tight control of membranecoupled actin assembly in the PAZ. 
Figure 6
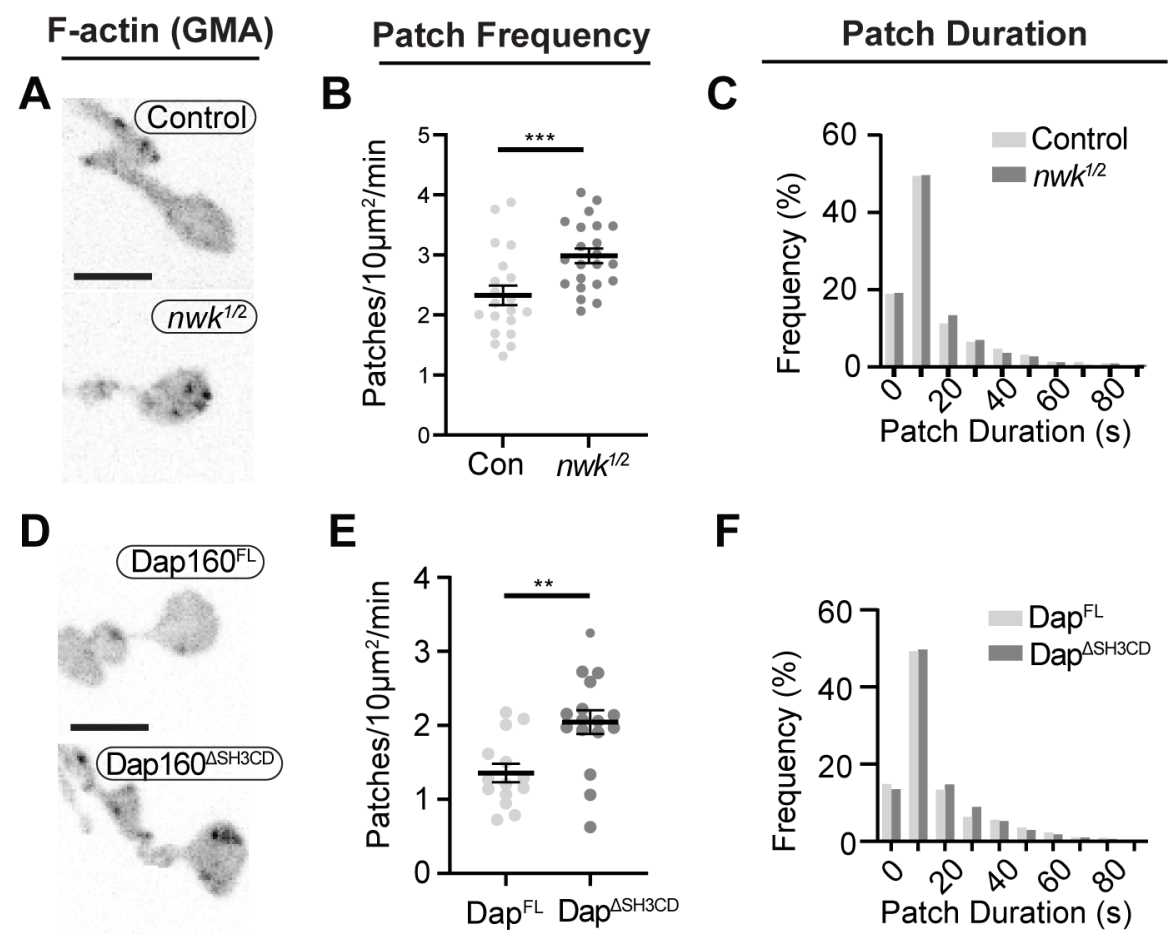

Figure 6. Loss of the Dap160-Nwk interaction disrupts actin patch dynamics at synapses in vivo. Quantification of GMA-labeled F-actin patch dynamics. (A,C) MaxIPs of live spinning disc confocal micrographs of GMA in the indicated genotypes, imaged at $1 \mathrm{~Hz}$. Graphs quantify patch frequency $(\mathrm{B}, \mathrm{E})$ and distribution of patch durations $(\mathrm{C}, \mathrm{F})$ and. Loss of each of $n w k(\mathrm{~A}-\mathrm{C})$ increases the frequency of patches. Similarly, loss of the Nwk-interacting Dap $160^{\mathrm{SH} 3 \mathrm{CD}}$ domain increases the frequency of patch assembly events, with no change in patch durations. Scale bars in (A,D) are 5 $\mu \mathrm{m}$. Associated with Fig 6 S1, Movie 2.

\section{Dap160-Nwk interactions regulate synaptic F-actin patch dynamics}

To determine how these mechanisms direct WASp-mediated actin assembly at the synapse, we measured actin dynamics in $n w k$ (Fig 6A-C, Movie 2) and dap160 domain (Fig 6D-F) mutant NMJs. We predicted two possible but non-exclusive functions based on the dual roles that we found for the Nwk-Dap160-WASp module in vitro: If Nwk and Dap160 are primary activators of WASp, then loss of function mutants are likely to diminish patch frequency, duration, or intensity. Importantly, multiple WASp activators exist in the synaptic endocytic machinery (e.g. Cip4 and Snx9 (Almeida-Souza et al., 2018; Gallop et al., 2013)), and therefore it would be possible that these could make significant contributions to WASp activation in addition to Nwk. Conversely, if an important function of autoinhibition is to 'clamp' actin assembly at the synapse, we expect that loss of Nwk and/or Dap160 would lead to spurious actin assembly events by these other WASp regulators. Strikingly, both $n w k$ and Dap160 ${ }^{\triangle \mathrm{SH} 3 \mathrm{CD}}$ mutants significantly increased patch frequency (Fig 6B,E), supporting a clamp function for these proteins. We did not find a difference in the distribution of patch lifetimes, suggesting that it is the frequency of events, and not their duration per se, that changes (Fig 6C,F).

We also analyzed actin dynamics using a complementary approach in which we measured the normalized intensity variation $(\mathrm{CoV})$ over time across the entire NMJ. Interestingly, the magnitude of variation was significantly higher in $n w k$ mutants (Fig 6S1A-B), but the area of the NMJ that was highly variant was similar between genotypes, suggesting that actin assembly is more dynamic in time in these mutants, rather than more extensive in space (Fig 6S1C). We validated this analysis for its sensitivity in detecting changes in event frequency by analyzing synthetic data (Fig 6S1D, see Methods for detail). The modeled data suggest that the difference in $\mathrm{CoV}$ that we measure between Control and nwk is consistent with a $43 \%$ increase in patch frequency, which is slightly higher than our measurement by particle tracking ( $28 \%$, Fig 6A). This complementary analysis does not rely on particle tracking and makes no assumptions about the nature of actin dynamics, and is consistent with our particle-based metrics. Thus, we conclude that these phenotypes are robust to the method of analysis used.

\section{Nwk and Dap160 ${ }^{S H C D}$ are required for normal synaptic vesicle endocytosis}

We next investigated the physiological function of actin patches in vivo. Considering that patch morphology, frequency, and duration resembled endocytic dynamics, we first compared actin patches with the endocytic adapter AP $2 \alpha$. Like other endocytic proteins, endogenously tagged AP $2 \alpha::$ GFP was highly abundant at the synapse and localized across much of the presynaptic membrane both diffusely and in highly dynamic puncta, only a subset of which dynamically colocalized with actin patches (Fig 7A-B, Movie 3). By contrast, a majority of actin patches colocalized with AP2 $\alpha:$ :GFP (Fig 7B-C, Manders' M1 $=0.59+/-.09$ ) in single live images, consistent with a role in endocytosis for these actinenriched sites. To functionally test the hypothesis that actin patches are endocytic, we acutely disrupted endocytic dynamics using the temperature sensitive dominant negative dynamin $/ s h i^{\mathrm{TS} 1}$ allele. When imaged under restrictive conditions, shi disruption decreased the 
A
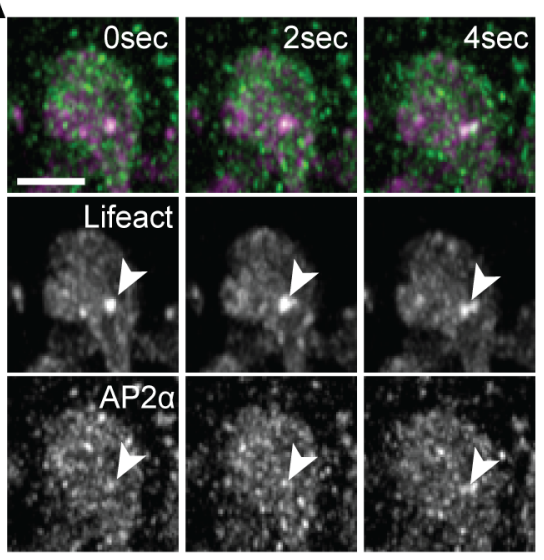

Lifeact::Ruby AP2a::GFP

$\mathbf{F}$

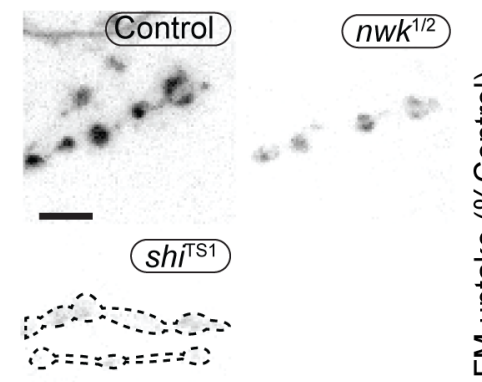

FM4-64fx
B

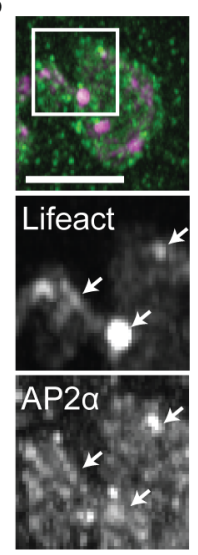

G

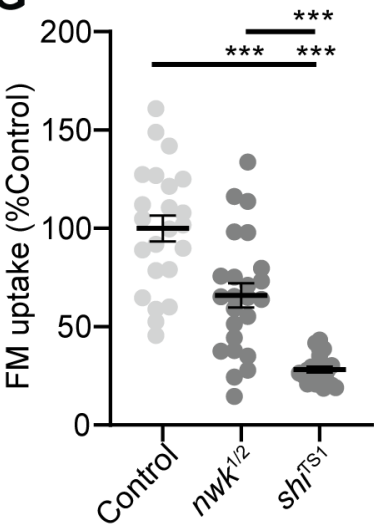

C
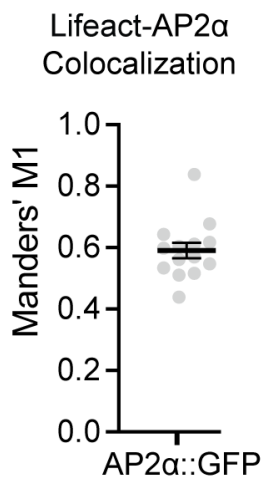

D

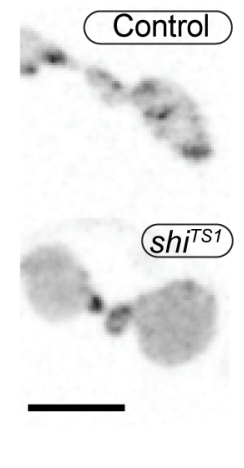

E

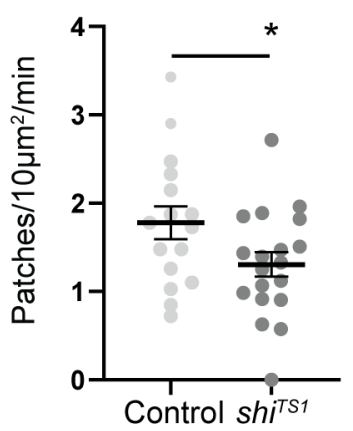

H

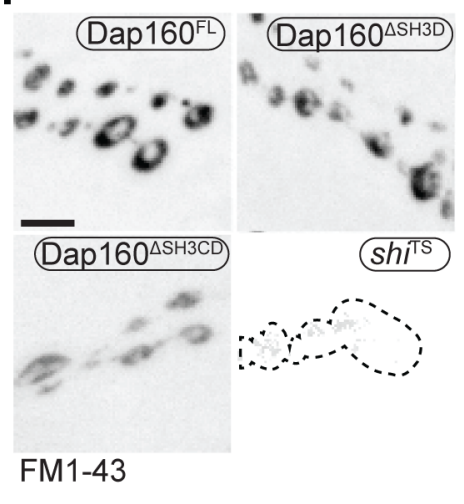

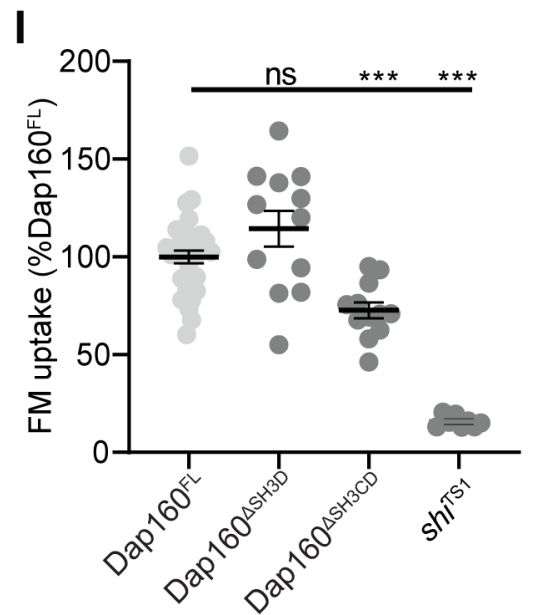

Figure 7. Actin patches and the Nwk-Dap160 interaction are associated with synaptic endocytosis. (A-B) MaxIPs of Airyscan micrographs of endogenously tagged AP2 $\alpha::$ GFP (green) and Lifeact::Ruby (magenta) in live (A) or fixed (B) preparations. Note AP2 $\alpha:$ GFP knockin is endogenously expressed in both neurons and muscle. (A) Timelapse showing dynamic colocalization of Lifeact::Ruby actin patches with AP2 $\alpha:$ GFP. (B-C) A majority of actin patches colocalize with presynaptic AP2 $\alpha:$ GFP signal. (C) Quantification of colocalization by Manders' coefficients. M1 represents $\%$ of lifeact region that contains AP2 $\alpha$ ::GFP signal above threshold. (D-E) Normal patch assembly requires Dynamin activity. (D) MaxIPs of single spinning disk confocal microscopy time points, showing pan-neuronally expressed GFP::actin in control and $s h i^{\mathrm{TS} 1} \mathrm{mutant} \mathrm{m} 6 / 7 \mathrm{NMJs}$, imaged at 1 $\mathrm{Hz}$, at the restrictive temperature of $31^{\circ}$ under stimulating conditions to drive the terminal $s h i^{\mathrm{TS} 1}$ phenotype $(45 \mathrm{mM} \mathrm{KCl}, 2 \mathrm{mM} \mathrm{CaCl} 2)$. Graph shows mean +/- s.e.m. n represents NMJs. (E) Quantification of patch frequency. (F-I) FM dye uptake assays at m6/7 NMJs following 5 min 90 mM potassium stimulation at $36^{\circ} \mathrm{C}$. (A,C) MaxIPs of spinning disc confocal micrographs of FM dye uptake assays. (A-B) $n w k$ mutants exhibit partially defective FM4-64fx dye uptake relative to $s h i^{\mathrm{TS} 1}$ mutants. (C-D) Loss of Dap160-Nwk interactions in a Dap160 ${ }^{\Delta \mathrm{SH} 3 \mathrm{CD}}$ truncation (but not Dap160 ${ }^{\Delta \mathrm{SH} 3 \mathrm{D}}$ ) exhibit partially defective FM1-43 dye uptake relative to $s h i^{\mathrm{TS} 1}$, similar to $n w k$ mutants. Graphs show mean $+/-$ s.e.m. ; n represents NMJs. Scale bars are 2.5 $\mu \mathrm{m}(\mathrm{A}, \mathrm{B})$ or $5 \mu \mathrm{m}(\mathrm{D}, \mathrm{F}, \mathrm{H})$. Associated with Fig 7 S1-2.

frequency of actin patch dynamics (Fig 7D-E). Together, these data suggest that a significant fraction of presynaptic actin patches are associated with endocytosis.

We next tested the physiological requirement of the Nwk and Dap160 ${ }^{\mathrm{SH} 3 \mathrm{CD}}$ interaction. As both Nwk and Dap160 are implicated in the endocytic trafficking of synaptic growth-promoting BMP receptors (O'Connor-Giles 2008, Rodal 2008), we tested whether the Dap160-Nwk interaction was required for normal synaptic growth, which we assayed by counting satellite boutons, a hallmark phenotype of both null mutants. Surprisingly, we found that both Dap160 $10^{\triangle \mathrm{SH} 3 \mathrm{D}}$ and Dap160 $0^{\triangle \mathrm{SH} H \mathrm{CD}}$ truncations rescued satellite bouton numbers to wild type levels (Fig 7S2), suggesting that actin dynamics phenotypes in the Dap $160^{\triangle \mathrm{SH} H C D}$ mutant are not associated with synaptic growth regulation. We next examined synaptic vesicle endocytosis and recycling by FM dye uptake. $n w k^{1 / 2}$ null mutants led to a $34 \%$ decrease in FM4-64fx uptake compared to controls (Fig 7A-B), an intermediate phenotype compared to dominant negative dynamin in $s h i^{\mathrm{TS} 1}$ mutants (FM uptake $28 \%$ of controls). dap 160 null mutants have been previously shown to exhibit an endocytosis defect (Koh et al., 2004; Marie et al., 2004), so we next tested whether the interaction between Dap160 and Nwk is required to support normal endocytosis. Indeed, we found that expression Dap $160^{\triangle \mathrm{SH} 3 \mathrm{CD}}$ in dap160 null mutants also significantly diminished FM dye uptake to a similar extent as loss of $n w k(27 \%$ reduction, Fig 7C-D). By contrast, loss of the Dap $160^{\text {SH3D }}$ domain alone caused no defects in FM uptake, consistent with the lack of effect of this mutation on Nwk accumulation and localization (Fig 3D-E), and suggesting that this interaction, though 
required in vitro, may be compensated by additional factors in vivo. Both $n w k$ and Dap160 $16 \mathrm{SH} 3 \mathrm{CD}$ mutants unloaded FM dye to the same extent as controls, suggesting that diminished endocytosis is a direct phenotype, and not secondary to exocytic deficits (Fig 7S1). Importantly, these data indicate that spurious actin assembly events in $n w k$ and dap160 mutants are likely to be unproductive for normal endocytosis. Overall, our data support the hypothesis that normal synaptic actin patches represent active endocytic events, and indicate that Dap160-Nwk regulation of actin patch dynamics is functionally required for synaptic vesicle endocytosis.

\section{Discussion}

Here we identify a mechanism by which autoinhibition clamps the presynaptic endocytic machinery to regulate the dynamics of discrete synaptic actin assembly events and the efficiency of synaptic endocytosis. We identify specific interactions among Nwk, Dap160, and WASp that function in two ways to potentiate membrane associated actin dynamics: 1) Persistent autoinhibition of Nwk allows for stable binding of inactive PAZ machinery to presynaptic membranes to constrain spurious actin assembly events. 2) Coordinated relief of Nwk autoinhibition by Dap160 and WASp robustly activate F-actin assembly and ensure that actin assembles into structures that are likely to productively remodel membranes. This provides a mechanism by which synapses can use the micron-scale PAZ organization of endocytic machinery as a regulated reservoir to efficiently generate $50-100 \mathrm{~nm}$ scale endocytic events, in response to physiological cues such as synaptic transmission.

\section{The predominant presynaptic actin structures resemble endocytic patches}

Here we provide the first quantitative analysis of the composition and dynamics of individual presynaptic F-actin structures. Numerous studies have examined actin dynamics at the level of entire synapses or qualitatively described dynamics of discrete actin structures (Bloom et al., 2003; Colicos et al., 2001; Nunes et al., 2006; Piccioli and Littleton, 2014; Sankaranarayanan et al., 2003; Zhao et al., 2013), and identified diverse roles for actin, including synaptic vesicle endocytosis (Holt et al., 2003; Kononenko et al., 2014; Soykan et al., 2017; Watanabe et al., 2013; Wu et al., 2016; Zhao et al, 2013), synaptic vesicle organization and mobilization (Guzman et al., 2019; Lee et al., 2012; Marra et al., 2012; Owe et al., 2009; Sakaba and Neher, 2003; Wolf et al., 2015), active zone organization and function (Boyl et al., 2007; Morales et al., 2000; Wagh et al., 2015; Waites et al., 2011; Wang et al., 1999), and receptormediated endocytosis (Kim et al., 2019; Rodal et al., 2008). Bulk analyses, which do not separate individual dynamic actin structures in space and time, are limited in their ability to discern how the regulation and dynamics of actin contribute to these distinct functions. We leveraged our ability to extract data describing individual structures to find that synaptic actin predominantly assembled into discrete Arp2/3associated patches, and identified points of control over their dynamics. Specifically, we found that loss of endocytic proteins differentially affected the frequency and kinetics of individual actin patches, which correlate with functional deficits in endocytosis.

The link between the actin structures that we observe and endocytic events is supported by several lines of evidence: The morphology and duration of synaptic actin patches are similar to WASp/Arp2/3-dependent endocytic actin dynamics in cultured mammalian cells ( $\sim 40$ seconds; Merrifield et al., 2004; Taylor et al., 2011). The frequency of patch assembly, which we measured in resting synapses, approaches the rate of spontaneous synaptic vesicle release at this synapse (Fig S1G) $(\sim 5-6 / 10$ $\mu \mathrm{m}^{2} / \mathrm{min}$; Melom et al., 2013, Akbergenova 2018). Further, actin patches colocalize partially with endocytic adapters and their assembly is sensitive to disruption of endocytosis (Fig 7D-E). Finally, we found that the same endocytic proteins and protein interactions that regulate endocytosis at this synapse also alter the dynamics of actin patches.

Technical challenges due to the high density of endocytic proteins and synaptic vesicle cargoes, and the difficulty of conducting sparse single vesicle measurements at this synapse (compared to neurons in culture (Chanaday and Kavalali, 2018; Peng et al., 2012)) make it difficult to directly link the dynamics of actin structures to specific membrane or cargo internalization events. However, the frequency of the events captured by our approach makes it unlikely that they represent rare Factin-dependent events at this synapse, such as those that control macropinocytosis or new bouton growth (Khuong et al., 2010; Kim et al., 2019; Piccioli and Littleton, 2014), and more likely that they represent bona fide endocytic events. Thus, while we do not rule out other biological functions for a subset of patches, together our data indicate that a significant and measurable fraction of synaptic actin patches are associated with endocytosis.

\section{Autoinhibition clamps PAZ membrane remodeling machinery at synapses}

Our data demonstrate that much of the synaptic membrane remodeling machinery is held in an inactive state at the presynaptic membrane: Nwk and Dap160 accumulate in a micron-scale membrane domain (Figs 1A, S1A, 3C), and loss of this machinery increases the frequency of shortlived actin patches (Fig 6). These data suggest that these PAZ proteins are held in a partially autoinhibited state at the membrane in vivo, consistent with our prior in vitro observations (Stanishneva-Konovalova et al., 2016). The fact that loss of Nwk increases the frequency of patches while decreasing FM uptake suggests that the actin structures assembled in the $n w k$ mutant are unproductive for synaptic vesicle endocytosis. These spurious patches could reflect non-specific actin assembly, perhaps due to unmasking of the Nwk ligand $\mathrm{PI}(4,5) \mathrm{P}_{2}$ at the membrane and/or inappropriate activation of alternative WASp-dependent actin assembly pathways. Indeed, additional WASp activators such as Snx9 and Cip4/Toca-1 may play accessory roles in endocytic actin assembly (Almeida-Souza et al., 2018; Gallop et al., 2013), consistent with our finding that loss of presynaptic WASp led to a decrease in the total number of patches (Fig 1E-G, Fig S1D-F). Our data indicate that at the synapse, where endocytic machinery accumulates at high concentrations (Wilhelm et al., 2014) and recruitment appears uncoupled from activation, these layers of autoregulation are critical to constrain actin assembly generally.

Our findings on autoinhibition and clamping connect two prevailing models of the organization and function of the synaptic endocytosis machinery- preassembly and delivery. In the first model, preassembly of clathrin and accessory proteins is hypothesized to ensure fast endocytosis in response to synaptic vesicle fusion (Hua et al., 2011; Mueller et al., 2004; Wienisch and Klingauf, 2006). Here, Nwk autoinhibition provides a mechanism to assemble an inactive, yet poised endocytic apparatus. In the second model, endocytic machinery associates with the synaptic vesicle pool, providing a ready source or buffer of proteins that can be released to the plasma membrane upon calcium signaling or vesicle fusion (Bai et al., 2010; Denker et al., 2011; Gerth et al., 2017; Winther et al., 2015). Because Dap160/Intersectin can shuttle between the synaptic vesicle pool and the plasma membrane, is itself subject to autoregulation (Gerth et al., 2017), and can regulate other endocytic proteins (e.g. Dynamin, Nwk), it could serve as a single activator that couples the preassembly and delivery models. 
bioRxiv preprint doi: https://doi.org/10.1101/2020.03.06.981076; this version posted December 5, 2020. The copyright holder for this preprint (which was not certified by peer review) is the author/funder, who has granted bioRxiv a license to display the preprint in perpetuity. It is made available under aCC-BY-NC-ND 4.0 International license.

Del Signore et al., 1242020 - BioRxiv

\section{Coordinated relief of autoinhibition restrains and directs membrane- associated actin dynamics}

Our in vitro data show that beyond functioning as a clamp, Nwk and Dap160 collaboratively activate WASp to promote robust actin assembly. Together with the defects we observed in vivo for actin dynamics and FM dye uptake, these data suggest that Dap160-NwkWASp interactions could serve as a coincidence detection mechanism to relieve autoinhibition of Nwk and promote productive actin assembly with other WASp activators. Coincidence detection mechanisms for Factin assembly have been demonstrated in several models of endocytosis (Case et al., 2019; Sun et al.), suggesting that amplification of WASp membrane binding could drive robust actin patch assembly at synapses. Similarly, in human cells, the interaction between FCHSD2, Intersectin, and WASp promotes actin assembly and endocytic maturation (AlmeidaSouza et al., 2018) or initiation (Xiao et al., 2018). The Dap160-Nwk module could act by directing and/or organizing actin assembly specifically at endocytic events, akin to the membrane directed actin assembly we observed in vitro (Fig 6C), and/or ensure that it is sufficiently robust for productive membrane remodeling (Akamatsu et al., 2020). Direct support for these models will require new analytical or imaging approaches to directly visualize the coupling of membranes and actin to the endocytic machinery, in order to distinguish spurious (due to unclamping) vs bona fide but underpowered endocytic actin assembly events.

\section{Physiological implications of autoregulatory mechanisms in the periactive zone}

Our data suggest that the endocytic machinery can be deployed as clamped, primed, or activated complexes at different locations at the synapse. The next critical step will be to determine how physiological cues such as calcium influx or synaptic vesicle release might recruit or activate Dap160 or WASp to regulate transitions between these states. One intriguing possibility is that these mechanisms might enable an endocytic periactive zones to rapidly switch between different modes of endocytosis (e.g. ultrafast, conventional, or bulk) in response to a wide range of synaptic activity patterns (Gan and Watanabe, 2018). These endocytic regulatory mechanisms could also be locally poised to regulate, respond, or adapt to the specific release properties of nearby active zones (Akbergenova et al., 2018; Melom et al., 2013), and serve as novel points of control over synaptic plasticity and homeostasis.

\section{STAR Methods}

\section{RESOURCE AVAILABILITY}

\section{Lead Contact}

Further information and requests for resources and reagents should be directed to and will be fulfilled by the Lead Contact, Avital Rodal (arodal@brandeis.edu).

Materials Availability

All plasmids and fly lines generated in these studies are available upon request.

\section{Data and Code Availability}

All custom FIJI/Image J and Python scripts used to analyze the data in these studies are available upon request.

\section{EXPERIMENTAL MODEL DETAILS}

Drosophila culture: Flies were cultured using standard media and techniques. All flies were raised at $25^{\circ} \mathrm{C}$, with the exception of experiments using Dcr2; Dap160 RNAi or WASp RNAi, for which flies were raised at $29^{\circ} \mathrm{C}$. See key resources table for all fly lines used and see Supplemental Table 1 for full genotypes for each experiment in this study.

\section{METHODS DETAILS}

Cloning: UAS-Dap160 constructs were generated in pBI-UASC-mCherry (derived from (Wang et al., 2011), see (Deshpande et al., 2016)). Fragments were amplified from the genomic Dap160 locus with primers described in the key resources table. These transgenes were injected into flies (Rainbow Gene), using $\Phi \mathrm{C} 31$-mediated integration at the Attp40 locus (Ni et al., 2008), to ensure that all constructs were in a similar genomic context. UAS-WASp-tev-myc was generated in pUAST (Brand and Perrimon, 1993) by inserting a TEV recognition site and 9 copies of the myc epitope tag at the $3^{\prime}$ end of the Wsp cDNA, and injected into $w^{1118}$ flies at the Duke Model Systems Transgenic Facility (Duke University, Durham, $\mathrm{NC}$ ).

Generation of AP2 $\alpha:$ :GFPKI : The vector pHD-sfGFP-dsRed was created using Gibson assembly by amplifying sfGFP from pScarlessHD-sfGFPDsRed (gift from Kate O'Connor-Giles, Addgene plasmid \# 80811) and inserting it in between the multiple cloning site and the first loxP site in the pHD-DsRed backbone (gift from Kate O'Connor-Giles, Addgene plasmid \# $51434) .1 \mathrm{~kb}$ sequences upstream and downstream of the stop codon were amplified from the genomic locus of AP2 $\alpha$ and inserted into pHD-sfGFPdsRed using Aarl and Sapl, respectively, to create the HDR donor pMM007 pHD-AP2a-C-sfGFP-dsRed. The guide RNA GGAAATCTGCGATCTGTTGA was cloned into pU6-Bbsl-chiRNA (gift from Melissa Harrison \& Kate O'Connor-Giles \& Jill Wildonger, Addgene plasmid \# 45946 (Gratz et al., 2013); using Bbsl to create pMM008_pU6AP2a-chiRNA. $500 \mathrm{ng} / \mathrm{uL}$ HDR donor plasmid and $100 \mathrm{ng} / \mathrm{uL}$ gRNA plasmid were injected into vas-Cas9(III) flies (BDSC 51324, injections by BestGene). Correct integration of the transgene was validated by sequencing

FM dye uptake: FM dye (FM1-43 in dap160 experiments, or FM4-64FX in nwk experiments) uptake experiments were performed essentially as described (Ramachandran and Budnik, 2010; Verstreken et al., 2008). For fixed experiments (nwk mutants), larvae were dissected in groups of 4-6 (with each dish having at least two control larvae) in low-calcium HL3 (Stewart et al., 1994), and axons were cut to dissociate CNS input. For live imaging (dap160 rescues), larvae were dissected, stained, and imaged in pairs, with one control (Dap160 ${ }^{\mathrm{FL}}$ ) and one experimental larva per dish. This temperature has been shown to exacerbate endocytic defects in some mutants, including dap160 (Koh et al., 2004). Following extensive washing in $\mathrm{Ca}^{++}$free saline, larvae were fixed in $4 \%$ paraformaldehyde in $\mathrm{Ca}^{++}$free saline (for $n w k$ experiments) or imaged live (for dap160 transgene rescue experiments). Images of muscle 6/7 NMJs (abdominal segments 3-5) were acquired by confocal microscopy and FM dye intensity was measured within mCherry (in dap160 experiments) or GFP (in nwk experiments)labeled presynaptic masks, and intensities were normalized to dishmatched control larvae. For unloading experiments, larvae were analyzed individually. In all experiments, dye loading $(4 \mu \mathrm{M})$ was performed in 90 $\mathrm{mM} \mathrm{KCl}, 2 \mathrm{mM} \mathrm{CaCl}{ }_{2} \mathrm{HL} 3$ saline for five minutes at $36^{\circ} \mathrm{C}$ on a submerged metal block using prewarmed buffer. For unloading, larvae were stimulated for an additional 5' with $90 \mathrm{mM} \mathrm{KCl} 2 \mathrm{mM} \mathrm{CaCl}_{2}$, washed extensively in Ca++ free HL3, then imaged and analyzed as for fixed larvae.

Immunohistochemistry: For analysis of NMJ morphology and protein localization, flies were cultured at low density at $25^{\circ} \mathrm{C}$. Wandering third instar larvae were dissected in calcium-free HL3.1 saline (Feng et al., 2004) and fixed for $30 \mathrm{~min}$ in HL3.1 containing 4\% formaldehyde. For analysis of NMJ overgrowth (satellite boutons), samples were stained with anti-HRP and anti-Dlg, and images were blinded before manual bouton counting. Boutons were counted on muscle $4 \mathrm{NMJs}$, abdominal segments $2-4$, and satellite boutons were defined as any string of fewer than five boutons that branched from the main NMJ branch (O'Connor-Giles et al., 2008).

Western blots: Drosophila heads (10 pooled/genotype) were homogenized in $100 \mu \mathrm{L} 2 \mathrm{x}$ Laemmli buffer. 10uL of extract per lane were fractionated by SDS/PAGE and immunoblotted with $\alpha$-Dap160 (Roos 1998 ) and $\alpha$-Tubulin antibodies (clone B-5-1-2, Sigma), and infraredconjugated secondary antibodies (Rockland, Inc). Blots were analyzed on a Biorad Chemidoc system,

Imaging and analysis: Spinning-disk confocal imaging of Drosophila larvae was performed at room temperature (except shils1 experiments) on a Nikon Ni-E upright microscope equipped with $60 \times$ (NA 1.4) and 100× (NA 1.45) oil immersion objectives, a Yokogawa CSU-W1 spinning-disk head, and an Andor iXon 897 EMCCD camera. Images were collected using Nikon Elements AR software. For shis1 GFP::actin imaging experiments, temperature was controlled using a CherryTemp temperature control unit (Cherry Biotech).

FRAP data (Fig 3C) were acquired on a Zeiss 880 with Airy Scan in super resolution acquisition mode, using a 63X NA1.4 objective. Single Z-slices through the middle of individual boutons were acquired at $4 \mathrm{~Hz}$ for $90 \mathrm{sec}$, with manual focus adjustment. Following acquisition of two or three initial Z-stacks to assess prebleach intensity, $<220 \%$ of individual boutons were 
bioRxiv preprint doi: https://doi.org/10.1101/2020.03.06.981076; this version posted December 5, 2020. The copyright holder for this preprint (which was not certified by peer review) is the author/funder, who has granted bioRxiv a license to display the preprint in perpetuity. It is made available under aCC-BY-NC-ND 4.0 International license.

Del Signore et al., 1242020 - BioRxiv

photobleached by the 488 laser at .6 intensity and scan speed of 6 . Intensities of background, unbleached, and bleached ROls were acquired manually using FIJl, and bleached area was normalized to prebleach and unbleached ROls (to correct for imaging-induced photobleaching), and analyzed with GraphPad Prism.

Confocal imaging of GUVs and cell-sized water droplets was conducted at room temperature on a Marianas spinning disk confocal system (3I, Inc, Denver,CO), consisting of a Zeiss Observer Z1 microscope equipped with a Yokagawa CSU-X1 spinning disk confocal head, a QuantEM 512SC EMCCD camera, PLAN APOCHROMAT $63 \mathrm{X}$ or $100 \mathrm{x}$ oil immersion objectives (n.a. 1.4), a Photonics Instruments Micropoint photo-ablation device, and Slidebook software.

3D-Structured Illumination Microscopy (SIM) was performed on a Nikon NSIM E system (consisting of an inverted Eclipse Ti-E microscope, 100x (n.a 1.45) oil-immersion objective, and a Hamamatsu OrcaFLASH4 sCMOS camera). Channel alignment was calculated for each imaging session using tetraspeck beads (Invitrogen cat no. T-7284). Images were collected at room temperature with a regime of 3 grid orientations and 5 phases and were reconstructed using Nikon Elements software, using a theoretical, ideal OTF generated by the software. Super-resolution images of protein localization in live samples were acquired with a Zeiss 880FAS microscope in fast Airyscan mode with a 63X (NA1.4) oil immersion objective, using Zen Blue software.

Analysis of actin dynamics at the NMJ: Spinning disk confocal time series were acquired at 15 stacks/min, except for experiments in Fig 6D-F, which were acquired at 60 stacks/min. A maximum intensity projection was made of each time point, movies were registered using the FIJI plugin StackReg, and analyzed by Patchtracker (Berro and Pollard, 2014) as follows: The threshold for patch detection was normalized to the mean probe intensity in the presynaptic area (threshold=Probe Mean * 0.40 ). All other settings for patch detection and tracking were default: Estimated patch diameter $.6 \mu \mathrm{m}$, median filter=false, subpixel detection=true. Linking max distance $=.5 \mu \mathrm{m}$, Gap-closing distance $=.5 \mu \mathrm{m}$, Gap-closing frame gap $=0$. For $.25 \mathrm{~Hz}$ imaging experiments, patches between $16-356 \mathrm{~s}$ could be detected. For $1 \mathrm{~Hz}$ imaging experiments, patches between 4-139s could be detected. Because this analysis rejects a significant number of detected patches due to tracking defects or tracking path overlap, we estimated the true patch frequency as follows: We combined detections from $0.25 \mathrm{~Hz}$ and $1 \mathrm{~Hz}$ imaging experiments by averaging the frequencies over the shared detection range (20-150 seconds) and adding the lower and higher duration patches that were specific to each imaging regime (4-16 seconds for $1 \mathrm{~Hz}$ and $150-360$ seconds for $0.25 \mathrm{~Hz}$ ). Then we 'corrected' for rejected tracks, and considered the lower bound of the estimate to be the actual, uncorrected merged frequency of detection $(2.8$ patches $/ 10 \mu \mathrm{m} / \mathrm{min})$ and the upper bound to be include every rejected track (10.3 patches/10 $\mu \mathrm{m} / \mathrm{min})$.

Actin dynamics were also analyzed by measuring intensity variation over time over the entire NMJ, i.e. without thresholding or particle tracking. We measured this by extracting the intensity value for each pixel over time and calculating the coefficient of variation (CoV, StdDev/Mean) for each pixel. We estimated the percentage of 'highly variant' pixels by thresholding these values using $\mathrm{Li}$ ( $\mathrm{Li}$ and Tam, 1998) and Moments (Tsai, 1995) algorithms. While these two algorithms gave different estimates of the fraction of NMJs covered by highly variant pixels, both indicated the same relationship between genotypes. To validate this approach we created synthetic data using a custom FIJ script, with a spatial and temporal scale that matched our in vivo imaging, and in which we varied parameters expected to impact this metric (signal intensity, noise level, fraction of dynamic pixels, dynamics frequency, dynamics duration, dynamics amplitude), and subjected the synthetic data to the same CoV over time analysis.

Intensity and Colocalization analysis: For intensity and colocalization, the presynaptic region was masked in 3D using a presynaptically enriched label: either HRP (Fig 3E, S4B), Nwk (Fig 1C, S1A, 3F), Dap160 (S1B), or Lifeact::ruby (Fig 2B). For mask generation, images were subjected to a gaussian blur filter and thresholded by intensity. Blur radius and the specific threshold algorithms used were empirically optimized for each experiment to consistently and accurately reflect the presynaptic area in control and mutant groups (and the same settings were used for all NMJs within any given experiment). Signal intensities were measured in 3D using a FIJI script, and colocalization analysis was performed in 3D on Airyscan or SIM reconstructed image stacks using the Coloc2 plugin for ImageJ (https://imagej.net/Coloc 2). For all images, background was subtracted using the rolling ball method with a radius of 50 pixels.

In vitro assays

Protein purification: Dap $160^{\mathrm{SH} 3 \mathrm{C}}$ and Dap $160^{\mathrm{SH} 3 \mathrm{CD}}$ were amplified from Dap160 Isoform A and cloned into pTrcHisA (see STAR methods for details) N-terminally His-Xpress-tagged proteins (Nwk ${ }^{1-633}$, Nwk-731, $\mathrm{Nwk}^{607-731}$, Nwk ${ }^{1-428}$, Wsp ${ }^{143-529}$, Dap $160^{\mathrm{SH} 3 \mathrm{C}}$, Dap160 $160^{\mathrm{SHCD}}$ ), were purified as described previously (Becalska et al., 2013; Kelley et al., 2015; Rodal et al., 2008; Stanishneva-Konovalova et al., 2016). In brief, proteins were purified from BL21(DE3) Escherichia coli using cobalt or nickel columns, followed by ion exchange and gel filtration into $20 \mathrm{mM}$ Tris $\mathrm{pH} 7.5,50 \mathrm{mM}$ $\mathrm{KCl}, 0.1 \mathrm{mM}$ EDTA, and $0.5 \mathrm{mM}$ DTT. GST fusions (Dap160 ${ }^{\mathrm{SH} 3 \mathrm{CD}}$ Dap160 ${ }^{\mathrm{SHC}}$, Dap160 ${ }^{\mathrm{SH}}$ ) were amplified from Dap160 isoform $A$ and cloned into pGEX4t (see STAR methods for details). Proteins were purified with glutathione agarose (Thermo Scientific, Waltham MA) in $20 \mathrm{mM}$ Tris $7.5,20 \mathrm{mM} \mathrm{KCl}$, and $0.5 \mathrm{mM}$ dithiothreitol (DTT) supplemented with protease inhibitors (P2714 (Sigma-Aldrich, St. Louis, MO) and $0.5 \mathrm{mg} / \mathrm{mL}$ pepstatin A). Arp2/3 complex was purchased from Cytoskeleton, Inc. Actin was purified from from acetone powder (Spudich and Watt, 1971) generated from frozen ground hind leg muscle tissue of young rabbits (PelFreez, Rogers, AR).

Coprecipitation assays: Coprecipitation with GST-tagged proteins were conducted as described previously (Kelley et al., 2015): Concentrations of GST fusions on beads were normalized using empty beads and bead volume was restricted to two-thirds of the total reaction volume. GST fusions were incubated with agitation with His-tagged target proteins at room temperature for one hour in binding buffer $(20 \mathrm{mM}$ Tris $\mathrm{pH} 8.0,20$ $\mathrm{mM} \mathrm{KCl}, 0.5 \mathrm{mM}$ DTT). For salt sensitivity experiments, the indicated concentrations of $\mathrm{NaCl}$ were used in place of $\mathrm{KCl}$ in the binding buffer. Beads were then pelleted and washed once with buffer after removing the supernatant. Pellets and supernatants were then boiled in Laemmli Sample Buffer and fractionated by SDS-PAGE, followed by Coomassie staining or immunoblotting as noted in figure legends, followed by imaging and analysis on a LICOR Odyssey device.

Liposome cosedimentation: Lipid cosedimentation assays were conducted as described previously (Becalska et al., 2013). In brief liposomes were swelled from dried lipid films in $20 \mathrm{mM}$ Hepes pH 7.5 and $100 \mathrm{mM} \mathrm{NaCl}$. Specific lipid compositions are indicated in the figure legends. Proteins were then mixed with $1 \mathrm{mg} / \mathrm{mL}$ liposomes, incubated for $30 \mathrm{~min}$ at room temperature, and then pelleted for $20 \mathrm{~min}$ at $18,000 \times \mathrm{g}$ at $4{ }^{\circ} \mathrm{C}$. Pellets and supernatants were then denatured in Laemmli sample buffer and fractionated by SDS/PAGE, followed by Coomassie staining, and imaging and analysis on a LICOR Odyssey device.

GUV decoration: GUVs were generated by gentle hydration. Briefly, 10 $\mu \mathrm{L}$ of $10 \mathrm{mg} / \mathrm{mL}$ lipids dissolved in 19:1 chloroform:methanol were dried under vacuum, then swelled in $300 \mu \mathrm{L}$ of $5 \mathrm{mM}$ HEPES $300 \mathrm{mM}$ sucrose, $\mathrm{pH} 7.5$ overnight at $70^{\circ} \mathrm{C}$. GUVs were imaged on a Marianas spinning disk confocal system (see above). $3 \mu \mathrm{L}$ GUVs were diluted into $5 \mathrm{mM}$ HEPES $150 \mathrm{mM} \mathrm{KCl} \mathrm{pH7.5,} \mathrm{incubated} \mathrm{with} \mathrm{protein} \mathrm{as} \mathrm{noted} \mathrm{in} \mathrm{figures,} \mathrm{and} \mathrm{imaged}$ using a 100X/ N.A. 1.4 objective in multiwell slides (Lab-Tek) precoated with $1 \mathrm{mg} / \mathrm{mL}$ BSA. After a $30 \mathrm{~min}$ incubation, $1 \%$ agarose in $5 \mathrm{mM}$ HEPES $150 \mathrm{mM} \mathrm{KCl} \mathrm{pH} 7.5$ was added (final agarose concentration .5\%) to limit GUV mobility. Images were analyzed by line tracing intensity profiles across a medial optical section of GUVs.

Actin assembly in droplets: Lipids (97.5\% DPHPC [1,2-diphytanoyl-snglycero-3-phosphocholine], Avanti Polar Lipids) and $2.5 \%$ DPHPC:PI $(4,5) \mathrm{P}_{2}$ ) were mixed in chloroform, dried under vacuum, and rehydrated to $23 \mathrm{mM}(20 \mathrm{mg} / \mathrm{ml})$ in decane. The indicated proteins were added to the lipid mix at a 1:50 volume ratio and pipetted vigorously until cloudy before imaging by spinning disk confocal microscopy.

Pyrene-actin assembly: Rabbit muscle actin $[5 \%$ (mol/mol) pyrenelabeled] was gel-filtered, prespun at $90,000 \times \mathrm{g}$, exchanged from $\mathrm{Ca}^{2+}$ to $\mathrm{Mg}^{2+}$, and assembled at a final concentration of $2.5 \mu \mathrm{M}$ as described previously (Moseley et al., 2006). Proteins were preincubated with 74 $\mu \mathrm{g} / \mathrm{mL}$ liposomes or control buffer for $30 \mathrm{~min}$ before actin assembly reactions. Assembly was monitored with a spectrofluorometer (Photon Technology International) using an excitation wavelength of $365 \mathrm{~nm}$ and an emission wavelength of $407 \mathrm{~nm}$. Rates were calculated from slopes of curves in the linear range, and curves were plotted using GraphPad Prism software.

\section{OUANTIFICATION AND STATISTICAL ANALYSIS}

Graphs were prepared and statistical analyses performed using Graphpad Prism software. For normally distributed data, comparisons were made using either T-test or ANOVA with posthoc Bonferroni's multiple comparisons test. For non-normally distributed data, comparisons were made using either Mann-Whitney $U$ test, or Kruskal-Wallis test with posthoc Dunn's test. Comparison of patch duration distributions was performed using a Kolmogorov-Smirnoff test. Please see Supplementa Table 1 for each statistical test performed for each experiment presented in this study. All data are shown as the mean +/- SEM.

\section{SUPPLEMENTAL MEDIA}

Supplemental Movie 1. Dynamics of actin patches labeled by complementary reporters. 

available under aCC-BY-NC-ND 4.0 International license.

Del Signore et al., 1242020 - BioRxiv

Supplemental Movie 2. Loss of $n w k$ increases the frequency of brief actin patches.

Supplemental Movie 3. AP2 $\alpha$ and Lifeact::Ruby partially colocalize.

\section{Author Contributions and Notes}

Conceptualization S.J.D, C.F.K, E.M.M, A.A.R. Methodology S.J.D, C.F.K, E.M.M, T.F., A.A.R. Software S.J.D. Formal Analysis S.J.D, C.F.K, M.F.M, E.M.M. Investigation S.J.D, C.F.K, E.M.M, T.L, M.F.M, B.E. Resources C.F.K, E.M.M, T.L, M.M, M.K. Data curation S.J.D, C.F.K, E.M.M, A.A.R. Writing - Original Draft S.J.D, C.F.K, A.A.R. Writing - Review \& Editing S.J.D, C.F.K, B.E, M.M, M.K, A.A.R. Visualization S.J.D, C.F.K, A.A.R. Supervision M.K, A.A.R. Project Administration A.A.R. Funding Acquisition M.K, A.A.R.

The authors declare no conflict of interest.

This article contains supporting information online.

\section{Acknowledgments}

The authors would like to thank Bruce Goode for actin reagents and advice, Julien Berro for particle tracking advice, Troy Littleton and Oleg Shupliakov for helpful discussions, Graeme Davis for anti-Dap160 antibody, and the Bloomington Drosophila Stock Center (Indiana University, Bloomington, IN, NIH P40OD018537) for providing fly stocks. This work was supported by a Basil O'Connor Scholar Award from the March of Dimes and a Pew Scholar award (AAR); by R01 NS116375 (AAR and TGF); by the Brandeis NSF MRSEC, Bioinspired Soft Materials (NSF-DMR 1420382); by T32 NS007292 (SJD), T32 GM007122 (CFK), and R90 DA03243501 (MFM); and by the Swiss National Science Foundation (grant 310030B_182825) and NCCR Chemical Biology funded by the SNSF (MK, MM).

\section{References}

Akamatsu, M., Vasan, R., Serwas, D., Ferrin, M.A., Rangamani, P., and Drubin, D.G. (2020). Principles of self-organization and load adaptation by the actin cytoskeleton during clathrin-mediated endocytosis. eLife 9, e49840.

Akbergenova, Y., Cunningham, K.L., Zhang, Y.V., Weiss, S., and Littleton, J.T. (2018). Characterization of developmental and molecular factors underlying release heterogeneity at Drosophila synapses. elife 7.

Almeida-Souza, L., Frank, R.A.W., García-Nafría, J., Colussi, A., Gunawardana, N., Johnson, C.M., Yu, M., Howard, G., Andrews, B., Vallis, Y., et al. (2018). A Flat BAR Protein Promotes Actin Polymerization at the Base of Clathrin-Coated Pits. Cell 174, 325337.e14.

Bai, J., Hu, Z., Dittman, J.S., Pym, E.C.G., and Kaplan, J.M. (2010). Endophilin functions as a membrane-bending molecule and is delivered to endocytic zones by exocytosis. Cell 143, 430-441.

Becalska, A.N., Kelley, C.F., Berciu, C., Stanishneva-Konovalova, T.B., Fu, X., Wang, S., Sokolova, O.S., Nicastro, D., and Rodal, A.A. (2013). Formation of membrane ridges and scallops by the F-BAR protein Nervous Wreck. Mol Biol Cell 24, 2406-2418.

Ben-Yaacov, S., Le Borgne, R., Abramson, I., Schweisguth, F., and Schejter, E.D. (2001). Wasp, the Drosophila Wiskott-Aldrich syndrome gene homologue, is required for cell fate decisions mediated by Notch signaling. J. Cell Biol. 152, 1-13.

Berro, J., and Pollard, T.D. (2014). Local and global analysis of endocytic patch dynamics in fission yeast using a new "temporal superresolution" realignment method. Mol. Biol. Cell 25, 3501-3514.

Bloom, O., Evergren, E., Tomilin, N., Kjaerulff, O., Löw, P., Brodin, L., Pieribone, V.A., Greengard, P., and Shupliakov, O. (2003). Colocalization of synapsin and actin during synaptic vesicle recycling. The Journal of Cell Biology 161, 737-747.
Boyl, P.P., Nardo, A.D., Mulle, C., Sassoè-Pognetto, M., Panzanelli, P., Mele, A., Kneussel, M., Costantini, V., Perlas, E., Massimi, M., et al. (2007). Profilin2 contributes to synaptic vesicle exocytosis, neuronal excitability, and novelty-seeking behavior. The EMBO Journal 26, 2991-3002.

Brand, A.H., and Perrimon, N. (1993). Targeted gene expression as a means of altering cell fates and generating dominant phenotypes. Development 118, 401-415.

Case, L.B., Zhang, X., Ditlev, J.A., and Rosen, M.K. (2019). Stoichiometry controls activity of phase-separated clusters of actin signaling proteins. Science 363, 1093-1097.

Chanaday, N.L., and Kavalali, E.T. (2018). Optical detection of three modes of endocytosis at hippocampal synapses. elife 7.

Colicos, M.A., Collins, B.E., Sailor, M.J., and Goda, Y. (2001). Remodeling of Synaptic Actin Induced by Photoconductive Stimulation. Cell 107, 605-616.

Collins, A., Warrington, A., Taylor, K.A., and Svitkina, T. (2011). Structural Organization of the Actin Cytoskeleton at Sites of Clathrin-Mediated Endocytosis. Current Biology 21, 1167-1175.

Coyle, I.P., Koh, Y.-H., Lee, W.-C.M., Slind, J., Fergestad, T., Littleton, J.T., and Ganetzky, B. (2004). Nervous wreck, an SH3 adaptor protein that interacts with Wsp, regulates synaptic growth in Drosophila. Neuron 41, 521-534.

Denker, A., Kröhnert, K., Bückers, J., Neher, E., and Rizzoli, S.O. (2011). The reserve pool of synaptic vesicles acts as a buffer for proteins involved in synaptic vesicle recycling. Proc. Natl. Acad. Sci. U.S.A. 108, 17183-17188.

Deshpande, M., Feiger, Z., Shilton, A.K., Luo, C.C., Silverman, E., and Rodal, A.A. (2016). Role of BMP receptor traffic in synaptic growth defects in an ALS model. Mol Biol Cell 27, 2898-2910.

Dickman, D.K., Lu, Z., Meinertzhagen, I.A., and Schwarz, T.L. (2006). Altered Synaptic Development and Active Zone Spacing in Endocytosis Mutants. Current Biology 16, 591-598.

Doyon, J.B., Zeitler, B., Cheng, J., Cheng, A.T., Cherone, J.M., Santiago, Y., Lee, A.H., Vo, T.D., Doyon, Y., Miller, J.C., et al. (2011). Rapid and efficient clathrin-mediated endocytosis revealed in genomeedited mammalian cells. Nat. Cell Biol. 13, 331-337.

Evergren, E., Gad, H., Walther, K., Sundborger, A., Tomilin, N., and Shupliakov, O. (2007). Intersectin is a negative regulator of dynamin recruitment to the synaptic endocytic zone in the central synapse. J. Neurosci. 27, 379-390.

Feng, Y., Ueda, A., and Wu, C.-F. (2004). A modified minimal hemolymphlike solution, HL3.1, for physiological recordings at the neuromuscular junctions of normal and mutant Drosophila larvae. J. Neurogenet. 18, 377-402.

Gallop, J.L., Walrant, A., Cantley, L.C., and Kirschner, M.W. (2013). Phosphoinositides and membrane curvature switch the mode of actin polymerization via selective recruitment of toca-1 and Snx9. Proc. Natl. Acad. Sci. U.S.A. 110, 7193-7198.

Gan, Q., and Watanabe, S. (2018). Synaptic Vesicle Endocytosis in Different Model Systems. Front. Cell. Neurosci. 12.

Gerth, F., Jäpel, M., Pechstein, A., Kochlamazashvili, G., Lehmann, M., Puchkov, D., Onofri, F., Benfenati, F., Nikonenko, A.G., Fredrich, K., et al. (2017). Intersectin associates with synapsin and regulates its nanoscale localization and function. Proc. Natl. Acad. Sci. U.S.A. 114, 12057-12062.

Grassart, A., Cheng, A.T., Hong, S.H., Zhang, F., Zenzer, N., Feng, Y., Briner, D.M., Davis, G.D., Malkov, D., and Drubin, D.G. (2014). Actin and dynamin2 dynamics and interplay during clathrin-mediated endocytosis. J. Cell Biol. 205, 721-735.

Gratz, S.J., Cummings, A.M., Nguyen, J.N., Hamm, D.C., Donohue, L.K., Harrison, M.M., Wildonger, J., and O'Connor-Giles, K.M. (2013). Genome engineering of Drosophila with the CRISPR RNA-guided Cas9 nuclease. Genetics 194, 1029-1035. 
bioRxiv preprint doi: https://doi.org/10.1101/2020.03.06.981076; this version posted December 5, 2020. The copyright holder for this preprint (which was not certified by peer review) is the author/funder, who has granted bioRxiv a license to display the preprint in perpetuity. It is made available under aCC-BY-NC-ND 4.0 International license.

Del Signore et al., 1242020 - BioRxiv

Guerrier, S., Coutinho-Budd, J., Sassa, T., Gresset, A., Jordan, N.V., Chen, K., Jin, W.-L., Frost, A., and Polleux, F. (2009). The F-BAR Domain of srGAP2 Induces Membrane Protrusions Required for Neuronal Migration and Morphogenesis. Cell 138, 990-1004.

Guzman, G.A., Guzman, R.E., Jordan, N., and Hidalgo, P. (2019). A Tripartite Interaction Among the Calcium Channel $\alpha 1$ - and $\beta$-Subunits and F-Actin Increases the Readily Releasable Pool of Vesicles and Its Recovery After Depletion. Front Cell Neurosci 13, 125.

Henne, W.M., Boucrot, E., Meinecke, M., Evergren, E., Vallis, Y., Mittal, R., and McMahon, H.T. (2010). FCHo Proteins Are Nucleators of Clathrin-Mediated Endocytosis. Science 328, 1281-1284.

Holt, M., Cooke, A., Wu, M.M., and Lagnado, L. (2003). Bulk membrane retrieval in the synaptic terminal of retinal bipolar cells. J. Neurosci. 23, 1329-1339.

Hua, Y., Sinha, R., Thiel, C.S., Schmidt, R., Hüve, J., Martens, H., Hell, S.W., Egner, A., and Klingauf, J. (2011). A readily retrievable pool of synaptic vesicles. Nature Neuroscience 14, 833-839.

Jäpel, M., Gerth, F., Sakaba, T., Bacetic, J., Yao, L., Koo, S.-J., Maritzen, T., Freund, C., and Haucke, V. (2020). Intersectin-Mediated Clearance of SNARE Complexes Is Required for Fast Neurotransmission. Cell Reports 30, 409-420.e6.

Kaempf, N., and Maritzen, T. (2017). Safeguards of Neurotransmission: Endocytic Adaptors as Regulators of Synaptic Vesicle Composition and Function. Front Cell Neurosci 11, 320.

Kaksonen, M., and Roux, A. (2018). Mechanisms of clathrin-mediated endocytosis. Nat. Rev. Mol. Cell Biol.

Kelley, C.F., Messelaar, E.M., Eskin, T.L., Wang, S., Song, K., Vishnia, K., Becalska, A.N., Shupliakov, O., Hagan, M.F., Danino, D., et al. (2015). Membrane Charge Directs the Outcome of F-BAR Domain Lipid Binding and Autoregulation. Cell Rep 13, 2597-2609.

Kessels, M.M., and Qualmann, B. (2004). The syndapin protein family: linking membrane trafficking with the cytoskeleton. Journal of Cell Science 117, 3077-3086.

Khuong, T.M., Habets, R.L.P., Slabbaert, J.R., and Verstreken, P. (2010). WASP is activated by phosphatidylinositol-4,5-bisphosphate to restrict synapse growth in a pathway parallel to bone morphogenetic protein signaling. Proc. Natl. Acad. Sci. U.S.A. 107, 17379-17384.

Kim, A.S., Kakalis, L.T., Abdul-Manan, N., Liu, G.A., and Rosen, M.K. (2000). Autoinhibition and activation mechanisms of the WiskottAldrich syndrome protein. Nature 404, 151-158.

Kim, N., Kim, S., Nahm, M., Kopke, D., Kim, J., Cho, E., Lee, M.-J., Lee, M., Kim, S.H., Broadie, K., et al. (2019). BMP-dependent synaptic development requires Abi-Abl-Rac signaling of BMP receptor macropinocytosis. Nat Commun 10, 684.

Koh, T.-W., Verstreken, P., and Bellen, H.J. (2004). Dap160/intersectin acts as a stabilizing scaffold required for synaptic development and vesicle endocytosis. Neuron 43, 193-205.

Koh, T.-W., Korolchuk, V.I., Wairkar, Y.P., Jiao, W., Evergren, E., Pan, H., Zhou, Y., Venken, K.J.T., Shupliakov, O., Robinson, I.M., et al. (2007). Eps15 and Dap160 control synaptic vesicle membrane retrieval and synapse development. J. Cell Biol. 178, 309-322.

Kononenko, N.L., Puchkov, D., Classen, G.A., Walter, A.M., Pechstein, A., Sawade, L., Kaempf, N., Trimbuch, T., Lorenz, D., Rosenmund, C., et al. (2014). Clathrin/AP-2 Mediate Synaptic Vesicle Reformation from Endosome-like Vacuoles but Are Not Essential for Membrane Retrieval at Central Synapses. Neuron 82, 981-988.

Lee, J.S., Ho, W.-K., and Lee, S.-H. (2012). Actin-dependent rapid recruitment of reluctant synaptic vesicles into a fast-releasing vesicle pool. Proc. Natl. Acad. Sci. U.S.A. 109, E765-774.

Madania, A., Dumoulin, P., Grava, S., Kitamoto, H., Schärer-Brodbeck, C., Soulard, A., Moreau, V., and Winsor, B. (1999). The Saccharomyces cerevisiae Homologue of Human Wiskott-Aldrich Syndrome Protein Las17p Interacts with the Arp2/3 Complex. MBoC 10, 3521-3538.
Marie, B., Sweeney, S.T., Poskanzer, K.E., Roos, J., Kelly, R.B., and Davis, G.W. (2004). Dap160/intersectin scaffolds the periactive zone to achieve high-fidelity endocytosis and normal synaptic growth. Neuron 43, 207-219.

Marra, V., Burden, J.J., Thorpe, J.R., Smith, I.T., Smith, S.L., Häusser, M., Branco, T., and Staras, K. (2012). A Preferentially Segregated Recycling Vesicle Pool of Limited Size Supports Neurotransmission in Native Central Synapses. Neuron 76, 579-589.

Meinecke, M., Boucrot, E., Camdere, G., Hon, W.-C., Mittal, R., and McMahon, H.T. (2013). Cooperative recruitment of dynamin and BIN/amphiphysin/Rvs (BAR) domain-containing proteins leads to GTP-dependent membrane scission. J. Biol. Chem. 288, 6651-6661.

Melom, J.E., Akbergenova, Y., Gavornik, J.P., and Littleton, J.T. (2013). Spontaneous and Evoked Release Are Independently Regulated at Individual Active Zones. J Neurosci 33, 17253-17263.

Merrifield, C.J., Qualmann, B., Kessels, M.M., and Almers, W. (2004). Neural Wiskott Aldrich Syndrome Protein (N-WASP) and the Arp2/3 complex are recruited to sites of clathrin-mediated endocytosis in cultured fibroblasts. Eur. J. Cell Biol. 83, 13-18.

Morales, M., Colicos, M.A., and Goda, Y. (2000). Actin-Dependent Regulation of Neurotransmitter Release at Central Synapses. Neuron 27, 539-550.

Moseley, J.B., Maiti, S., and Goode, B.L. (2006). Formin proteins: purification and measurement of effects on actin assembly. Meth. Enzymol. 406, 215-234.

Mueller, V.J., Wienisch, M., Nehring, R.B., and Klingauf, J. (2004). Monitoring clathrin-mediated endocytosis during synaptic activity. J. Neurosci. 24, 2004-2012.

Ni, J.-Q., Markstein, M., Binari, R., Pfeiffer, B., Liu, L.-P., Villalta, C., Booker, M., Perkins, L., and Perrimon, N. (2008). Vector and parameters for targeted transgenic RNA interference in Drosophila melanogaster. Nat. Methods 5, 49-51.

Nelson, J.C., Stavoe, A.K.H., and Colón-Ramos, D.A. (2013). The actin cytoskeleton in presynaptic assembly. Cell Adh Migr 7, 379-387.

Nunes, P., Haines, N., Kuppuswamy, V., Fleet, D.J., and Stewart, B.A. (2006). Synaptic Vesicle Mobility and Presynaptic F-Actin Are Disrupted in a N-ethylmaleimide-sensitive Factor Allele of Drosophila. MBoC 17, 4709-4719.

O'Connor-Giles, K.M., Ho, L.L., and Ganetzky, B. (2008). Nervous Wreck Interacts with Thickveins and the Endocytic Machinery to Attenuate Retrograde BMP Signaling during Synaptic Growth. Neuron 58, 507518.

Okamoto, M., Schoch, S., and Südhof, T.C. (1999). EHSH1/intersectin, a protein that contains $\mathrm{EH}$ and $\mathrm{SH} 3$ domains and binds to dynamin and SNAP-25. A protein connection between exocytosis and endocytosis? J. Biol. Chem. 274, 18446-18454.

Owe, S.G., Jensen, V., Evergren, E., Ruiz, A., Shupliakov, O., Kullmann, D.M., Storm-Mathisen, J., Walaas, S.I., Hvalby, Ø., and Bergersen, L.H. (2009). Synapsin- and Actin-Dependent Frequency Enhancement in Mouse Hippocampal Mossy Fiber Synapses. Cereb Cortex 19, 511-523.

Papandréou, M.-J., and Leterrier, C. (2018). The functional architecture of axonal actin. Mol. Cell. Neurosci. 91, 151-159.

Pawson, C., Eaton, B.A., and Davis, G.W. (2008). Formin-Dependent Synaptic Growth: Evidence That Dlar Signals via Diaphanous to Modulate Synaptic Actin and Dynamic Pioneer Microtubules. J. Neurosci. 28, 11111-11123.

Pechstein, A., Bacetic, J., Vahedi-Faridi, A., Gromova, K., Sundborger, A., Tomlin, N., Krainer, G., Vorontsova, O., Schäfer, J.G., Owe, S.G., et al. (2010). Regulation of synaptic vesicle recycling by complex formation between intersectin 1 and the clathrin adaptor complex AP2. Proc. Natl. Acad. Sci. U.S.A. 107, 4206-4211.

Pechstein, A., Gerth, F., Milosevic, I., Jäpel, M., Eichhorn-Grünig, M., Vorontsova, O., Bacetic, J., Maritzen, T., Shupliakov, O., Freund, C., 
bioRxiv preprint doi: https://doi.org/10.1101/2020.03.06.981076; this version posted December 5, 2020. The copyright holder for this preprint (which was not certified by peer review) is the author/funder, who has granted bioRxiv a license to display the preprint in perpetuity. It is made available under aCC-BY-NC-ND 4.0 International license.

Del Signore et al., 1242020 - BioRxiv

et al. (2015). Vesicle uncoating regulated by $\mathrm{SH} 3-\mathrm{SH} 3$ domainmediated complex formation between endophilin and intersectin at synapses. EMBO Rep. 16, 232-239.

Pelassa, I., Zhao, C., Pasche, M., Odermatt, B., and Lagnado, L. (2014). Synaptic vesicles are "primed" for fast clathrin-mediated endocytosis at the ribbon synapse. Front Mol Neurosci 7, 91-91.

Peng, A., Rotman, Z., Deng, P.-Y., and Klyachko, V.A. (2012). Differential Motion Dynamics of Synaptic Vesicles Undergoing Spontaneous and Activity-Evoked Endocytosis. Neuron 73, 1108-1115.

Piccioli, Z.D., and Littleton, J.T. (2014). Retrograde BMP Signaling Modulates Rapid Activity-Dependent Synaptic Growth via Presynaptic LIM Kinase Regulation of Cofilin. J. Neurosci. 34, 43714381.

Praefcke, G.J., Ford, M.G., Schmid, E.M., Olesen, L.E., Gallop, J.L., PeakChew, S.-Y., Vallis, Y., Babu, M.M., Mills, I.G., and McMahon, H.T. (2004). Evolving nature of the AP2 $\alpha$-appendage hub during clathrincoated vesicle endocytosis. The EMBO Journal 23, 4371-4383.

Pucharcos, C., Estivill, X., and de la Luna, S. (2000). Intersectin 2, a new multimodular protein involved in clathrin-mediated endocytosis11The sequence data reported in this paper have been submitted to GenBank and have been assigned the accession numbers AF182198 and AF182199. FEBS Letters 478, 43-51.

Ramachandran, P., and Budnik, V. (2010). FM1-43 Labeling of Drosophila Larval Neuromuscular Junctions. Cold Spring Harb Protoc 2010, pdb.prot5471.

Rao, Y., Ma, Q., Vahedi-Faridi, A., Sundborger, A., Pechstein, A., Puchkov, D., Luo, L., Shupliakov, O., Saenger, W., and Haucke, V. (2010). Molecular basis for $\mathrm{SH} 3$ domain regulation of F-BAR-mediated membrane deformation. Proc. Natl. Acad. Sci. U.S.A. 107, 82138218.

Reshetniak, S., Ußling, J.-E., Perego, E., Rammner, B., Schikorski, T., Fornasiero, E.F., Truckenbrodt, S., Köster, S., and Rizzoli, S.O. (2020). A comparative analysis of the mobility of 45 proteins in the synaptic bouton. The EMBO Journal 39, e104596.

Rodal, A.A., Motola-Barnes, R.N., and Littleton, J.T. (2008). Nervous wreck and Cdc42 cooperate to regulate endocytic actin assembly during synaptic growth. J. Neurosci. 28, 8316-8325.

Rodal, A.A., Blunk, A.D., Akbergenova, Y., Jorquera, R.A., Buhl, L.K., and Littleton, J.T. (2011). A presynaptic endosomal trafficking pathway controls synaptic growth signaling. J. Cell Biol. 193, 201-217.

Roos, J., and Kelly, R.B. (1998). Dap160, a neural-specific Eps15 homology and multiple $\mathrm{SH} 3$ domain-containing protein that interacts with Drosophila dynamin. J. Biol. Chem. 273, 19108-19119.

Sabeva, N., Cho, R.W., Vasin, A., Gonzalez, A., Littleton, J.T., and Bykhovskaia, M. (2017). Complexin Mutants Reveal Partial Segregation between Recycling Pathways That Drive Evoked and Spontaneous Neurotransmission. J. Neurosci. 37, 383-396.

Sakaba, T., and Neher, E. (2003). Involvement of Actin Polymerization in Vesicle Recruitment at the Calyx of Held Synapse. J. Neurosci. 23, 837-846.

Sankaranarayanan, S., Atluri, P.P., and Ryan, T.A. (2003). Actin has a molecular scaffolding, not propulsive, role in presynaptic function. Nat. Neurosci. 6, 127-135.

Schmid, E.M., Ford, M.G.J., Burtey, A., Praefcke, G.J.K., Peak-Chew, S.Y., Mills, I.G., Benmerah, A., and McMahon, H.T. (2006). Role of the AP2 $\beta$-Appendage Hub in Recruiting Partners for Clathrin-Coated Vesicle Assembly. PLOS Biology 4, e262.

Sengar, A.S., Wang, W., Bishay, J., Cohen, S., and Egan, S.E. (1999). The $\mathrm{EH}$ and $\mathrm{SH} 3$ domain Ese proteins regulate endocytosis by linking to dynamin and Eps15. EMBO J. 18, 1159-1171.

Sone, M., Suzuki, E., Hoshino, M., Hou, D., Kuromi, H., Fukata, M., Kuroda, S., Kaibuchi, K., Nabeshima, Y., and Hama, C. (2000). Synaptic development is controlled in the periactive zones of Drosophila synapses. Development 127, 4157-4168.
Soykan, T., Kaempf, N., Sakaba, T., Vollweiter, D., Goerdeler, F., Puchkov, D., Kononenko, N.L., and Haucke, V. (2017). Synaptic Vesicle Endocytosis Occurs on Multiple Timescales and Is Mediated by Formin-Dependent Actin Assembly. Neuron 93, 854-866.e4.

Spudich, J.A., and Watt, S. (1971). The regulation of rabbit skeletal muscle contraction. I. Biochemical studies of the interaction of the tropomyosin-troponin complex with actin and the proteolytic fragments of myosin. J. Biol. Chem. 246, 4866-4871.

Stanishneva-Konovalova, T.B., Kelley, C.F., Eskin, T.L., Messelaar, E.M., Wasserman, S.A., Sokolova, O.S., and Rodal, A.A. (2016). Coordinated autoinhibition of F-BAR domain membrane binding and WASp activation by Nervous Wreck. Proc. Natl. Acad. Sci. U.S.A. 113, E5552-5561.

Stewart, B.A., Atwood, H.L., Renger, J.J., Wang, J., and Wu, C.F. (1994). Improved stability of Drosophila larval neuromuscular preparations in haemolymph-like physiological solutions. J. Comp. Physiol. A 175, 179-191.

Sun, Y., Leong, N.T., Jiang, T., Tangara, A., Darzacq, X., and Drubin, D.G. Switch-like Arp2/3 activation upon WASP and WIP recruitment to an apparent threshold level by multivalent linker proteins in vivo. eLife 6 .

Taylor, M.J., Perrais, D., and Merrifield, C.J. (2011). A High Precision Survey of the Molecular Dynamics of Mammalian Clathrin-Mediated Endocytosis. PLOS Biology 9, e1000604.

Teckchandani, A., Mulkearns, E.E., Randolph, T.W., Toida, N., and Cooper, J.A. (2012). The clathrin adaptor Dab2 recruits EH domain scaffold proteins to regulate integrin $\beta 1$ endocytosis. Mol. Biol. Cell 23, 2905-2916.

Ukken, F.P., Bruckner, J.J., Weir, K.L., Hope, S.J., Sison, S.L., Birschbach, R.M., Hicks, L., Taylor, K.L., Dent, E.W., Gonsalvez, G.B., et al. (2016). BAR-SH3 sorting nexins are conserved interacting proteins of Nervous wreck that organize synapses and promote neurotransmission. J. Cell. Sci. 129, 166-177.

Verstreken, P., Ohyama, T., and Bellen, H.J. (2008). FM 1-43 labeling of synaptic vesicle pools at the Drosophila neuromuscular junction. Methods Mol. Biol. 440, 349-369.

Wagh, D., Terry-Lorenzo, R., Waites, C.L., Leal-Ortiz, S.A., Maas, C., Reimer, R.J., and Garner, C.C. (2015). Piccolo Directs Activity Dependent F-Actin Assembly from Presynaptic Active Zones via Daam1. PLOS ONE 10, e0120093.

Waites, C.L., Leal-Ortiz, S.A., Andlauer, T.F.M., Sigrist, S.J., and Garner, C.C. (2011). Piccolo Regulates the Dynamic Assembly of Presynaptic F-Actin. J. Neurosci. 31, 14250-14263.

Wang, D., Zhang, L., Zhao, G., Wahlström, G., Heino, T.I., Chen, J., and Zhang, Y.Q. (2010). Drosophila twinfilin is required for cell migration and synaptic endocytosis. J Cell Sci 123, 1546-1556.

Wang, J.-W., Brent, J.R., Tomlinson, A., Shneider, N.A., and McCabe, B.D. (2011). The ALS-associated proteins FUS and TDP-43 function together to affect Drosophila locomotion and life span. J. Clin. Invest. 121, 4118-4126.

Wang, X., Kibschull, M., Laue, M.M., Lichte, B., Petrasch-Parwez, E., and Kilimann, M.W. (1999). Aczonin, a 550-Kd Putative Scaffolding Protein of Presynaptic Active Zones, Shares Homology Regions with Rim and Bassoon and Binds Profilin. J Cell Biol 147, 151-162.

Watanabe, S., Rost, B.R., Camacho-Pérez, M., Davis, M.W., SöhlKielczynski, B., Rosenmund, C., and Jorgensen, E.M. (2013). Ultrafast endocytosis at mouse hippocampal synapses. Nature 504, 242-247.

Wienisch, M., and Klingauf, J. (2006). Vesicular proteins exocytosed and subsequently retrieved by compensatory endocytosis are nonidentical. Nat. Neurosci. 9, 1019-1027.

Wilhelm, B.G., Mandad, S., Truckenbrodt, S., Kröhnert, K., Schäfer, C., Rammner, B., Koo, S.J., Claßen, G.A., Krauss, M., Haucke, V., et al. (2014). Composition of isolated synaptic boutons reveals the amounts of vesicle trafficking proteins. Science $344,1023-1028$. 
bioRxiv preprint doi: https://doi.org/10.1101/2020.03.06.981076; this version posted December 5, 2020. The copyright holder for this preprint

(which was not certified by peer review) is the author/funder, who has granted bioRxiv a license to display the preprint in perpetuity. It is made available under aCC-BY-NC-ND 4.0 International license.

Del Signore et al., 1242020 - BioRxiv

Winther, A..M.E., Jiao, W., Vorontsova, O., Rees, K.A., Koh, T.-W., Sopova, E., Schulze, K.L., Bellen, H.J., and Shupliakov, O. (2013). The dynamin-binding domains of Dap160/intersectin affect bulk membrane retrieval in synapses. J. Cell. Sci. 126, 1021-1031.

Winther, Å.M.E., Vorontsova, O., Rees, K.A., Näreoja, T., Sopova, E., Jiao, W., and Shupliakov, O. (2015). An Endocytic Scaffolding Protein together with Synapsin Regulates Synaptic Vesicle Clustering in the Drosophila Neuromuscular Junction. J. Neurosci. 35, 14756-14770.

Wolf, M., Zimmermann, A.-M., Görlich, A., Gurniak, C.B., SassoèPognetto, M., Friauf, E., Witke, W., and Rust, M.B. (2015). ADF/Cofilin Controls Synaptic Actin Dynamics and Regulates Synaptic Vesicle Mobilization and Exocytosis. Cereb. Cortex 25, 2863-2875.

Wu, X.-S., Lee, S.H., Sheng, J., Zhang, Z., Zhao, W.-D., Wang, D., Jin, Y., Charnay, P., Ervasti, J.M., and Wu, L.-G. (2016). Actin Is Crucial for
All Kinetically Distinguishable Forms of Endocytosis at Synapses. Neuron 92, 1020-1035.

Xiao, G.-Y., and Schmid, S.L. (2020). FCHSD2 Controls Oncogenic ERK1/2 Signaling Outcome by Regulating Endocytic Trafficking. BioRxiv 2020.01.29.924449.

Xiao, G.-Y., Mohanakrishnan, A., and Schmid, S.L. (2018). Role for ERK1/2-dependent activation of FCHSD2 in cancer cell-selective regulation of clathrin-mediated endocytosis. PNAS 115, E9570E9579.

Zhao, L., Wang, D., Wang, Q., Rodal, A.A., and Zhang, Y.Q. (2013). Drosophila cyfip regulates synaptic development and endocytosis by suppressing filamentous actin assembly. PLoS Genet. 9, e1003450. 